\title{
Recent advances in microbial biosynthesis of C3 - C5 diols: Genetics and Process engineering approaches
}

Narisetty Vivek ${ }^{1}$, Sulfath Hakkim Hazeena ${ }^{2,3}$, Maria Paul Alphy ${ }^{2,3}$, Vinod Kumar ${ }^{1}$, Sara Magdouli ${ }^{4}$, Raveendran Sindhu ${ }^{2}$, Ashok Pandey ${ }^{5}$ and Parameswaran Binod ${ }^{2,3 *}$

${ }^{1}$ Centre for Climate and Environmental Protection, School of Water, Energy and Environment, Cranfield University, Cranfield MK43 OAL, UK

${ }^{2}$ Microbial Processes and Technology Division, CSIR-National Institute for Interdisciplinary Science and Technology (CSIR-NIIST), Thiruvananthapuram 695 019, Kerala, India

${ }^{3}$ Academy of Scientific and Innovative Research (AcSIR), Ghaziabad - 201002 , India ${ }^{4}$ Centre technologique des résidus industriels, University of Quebec in Abitibi Témiscamingue, Quebec, Canada

${ }^{5}$ Centre for Innovation and Translational Research CSIR-Indian Institute of Toxicology Research (CSIR-IITR), 31MG Marg, Lucknow-226 001, India

*Corresponding author. Tel: 91-471-2515361, Fax: 91-471-2491712

E-mail: binodkannur@niist.res.in 


\section{Graphical abstract}

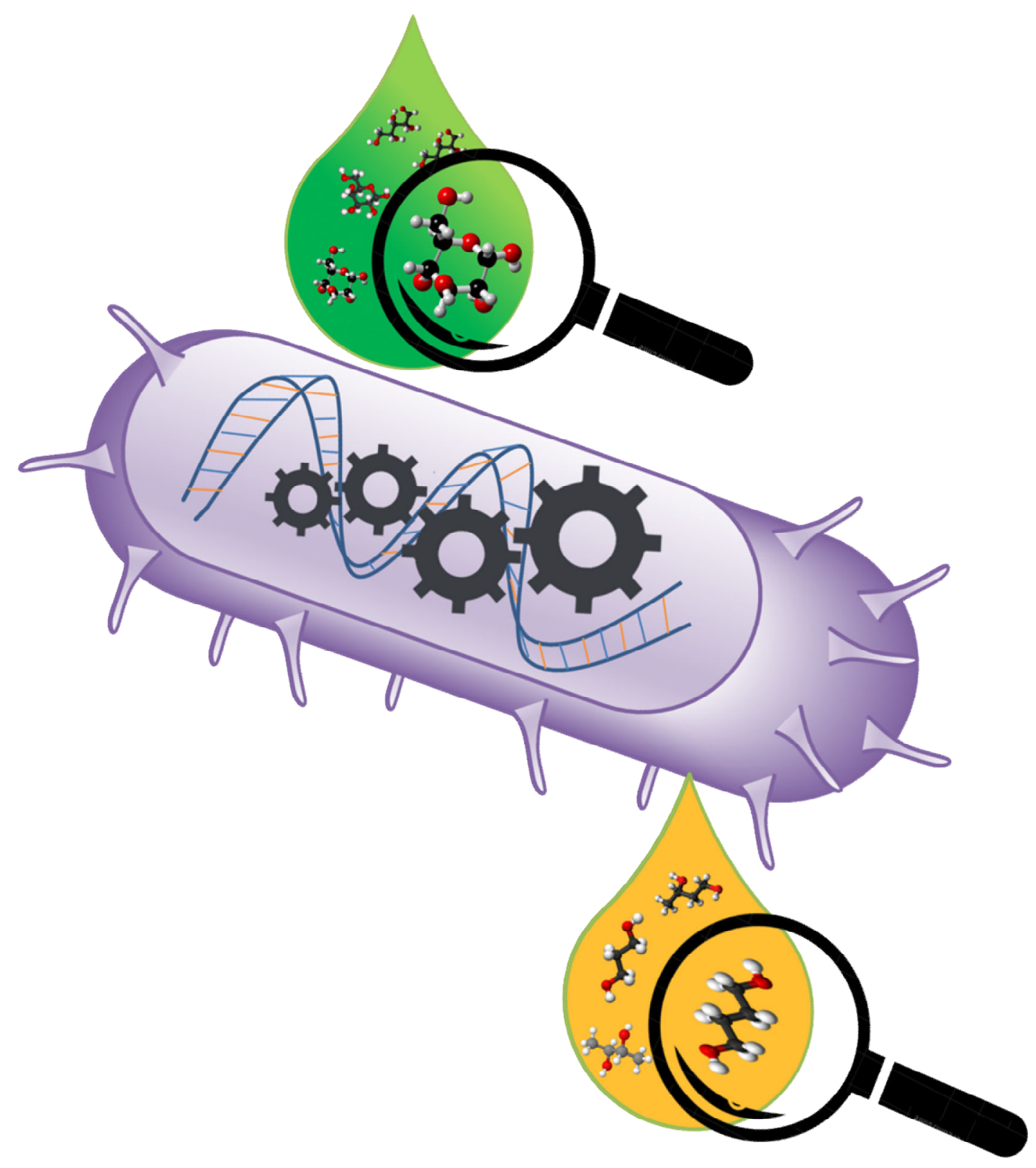




\section{Highlights}

- Overview of native and non-native microorganisms for synthesis of C3-C5 diols.

- Spectrum of renewable and sustainable feedstocks for C3-C5 diols synthesis.

- Media engineering and process optimization strategies for improving yield.

- Requisites for efficient and sustainable commercial bioprocess for C3-C5 diols. 


\begin{abstract}
Diols derived from renewable feedstocks have significant commercial interest in polymer, pharmaceutical, cosmetics, flavors and fragrances, food and feed industries. In C3-C5 diols biological processes of 1, 3-propanediol, 1, 2-propanediol and 2, 3-butanediol have been commercialized as other isomers are non-natural metabolites and lack natural biosynthetic pathways. However, the developments in the field of systems and synthetic biology paved a new path to learn, build, construct, and test for efficient chassis strains. The current review addresses the recent advancements in metabolic engineering, construction of novel pathways, process developments aimed at enhancing in production of $\mathrm{C} 3-\mathrm{C} 5$ diols. The requisites on developing an efficient and sustainable commercial bioprocess for C3-C5 diols were also discussed.
\end{abstract}

Keywords: Metabolic engineering; Propanediols; Butanediols; Pentanediols; Renewable 


\section{Introduction}

Before the advancements in the petroleum and chemical industry, most of the commercial fuels (ethanol, butanol), organic acids (lactic acid, acetic acid), and other bulk and speciality chemicals were produced through biological methods by using renewable substrates. Later petrochemical or fossil-based processes have replaced few of these biological processes due to their ease and cost-effectiveness in product formation.

Diols and their derivatives are the molecules of commercial interests with their applications as platform bulk and speciality chemicals in food, pharmaceutical and polymer industries. For example, diols are used in synthesis of polymers, polyesters, and polyurethanes that can be used in synthesis of bioplastics. Plastics are usually synthetic or semi-synthetic organic polymers derived from petrochemicals. Due to their lower cost, these polymers, either as such or with additives, are used in from household items to electronics, aerospace technologies, and agricultural sector to medical and pharma industries (Chung et al., 2015; Sabra et al., 2016; Zeng and Sabra, 2011a; Zhang et al., 2017). But what are the consequences of using it? These organic polymers are durable and degrade slowly, as the chemical composition of these polymers is resistant to natural degradation processes and imperviousness to water. As these are hard to remove from the environment, they pose a significant threat to the land and aquatic ecosystem. By the increase of plastic consumption, plastic waste accumulation and/or pollution have become a global concern. It is worth mentioning that in 2015 , between 60 and 99 metric tonnes of mismanaged plastics were produced worldwide and this is estimated to increase up to 155 to 266 metric tonnes by 2060. In fact, the concept of biopolymers and their commercialization has become a requisite. Biopolymers, bio-polyesters, proteins, polysaccharides can replace the petrochemical derivatives, as these components have functional properties that attribute in the synthesis of films for the packaging industry and other applications (Van Den Broek et al., 2015). In projective estimation, it is predicted that 
global biopolymer production will grow up from 2.11 million tonnes in 2019 to 2.42 million tonnes by 2024. According to Ted Hughes "Nothing is free, everything has to be paid for", so how easily the fossil-based resources are turned into chemicals, fuels and other materials; they jeopardize the environmental and global security.

Ethylene glycol, propanediols (PDO), butanediols (BDO) and pentanediols (PeDO) are very interesting chemicals with commercial interests in the fields of cosmetics, solvents, fuels, polymers, pharmaceuticals, biomedicine and animal feed. Commercially well-known polymers polyethylene terephthalate (PET), polytrimethylene terephthalate (PTT) and polybutylene terephthalate (PBT) are synthesized from ethylene glycol, 1, 3-propanediol, and 2, 3-butanediol respectively. The synthesis of polyester involves two simple reactions; an initial transesterification of diol with a dicarboxylic acid in the presence of a metallic catalyst in an inert atmosphere and finally polycondensation reaction at a higher temperature (Vivek et al., 2019). Currently 18 million tonnes of diols are produced annually from fossil-based processes, but these compounds can be produced through biological processes using renewable feedstocks and waste streams generated from industries (Vivek et al., 2019).

Various isoforms of these C3-C5 diols are known C3 (1, 3-PDO, 1, 2-PDO), C4 (2, 3-BDO, 1, 4-BDO, 1, 3-BDO), and C5 (1, 5-PeDO, 1, 3-PeDO, 2, 4-PeDO). Out of these diols, only 1, 3-PDO, 1, 2-PDO and 2, 3-BDO are well evaluated and can be naturally produced from wild type microorganisms while the other isomers are synthesized either via biotransformation from immediate precursors or through synthetic and non-natural biosynthetic pathways (table 1).

In this study, recent developments in strain engineering, process optimization, especially on designing new metabolic pathways, tools and techniques applied to improve the microbial production of C3-C5 diols have been thoroughly reviewed. Along with progress made, a brief 
discussion on challenges and limitations to be focussed on developing a sustainable process for commercial scale and economical manufacturing of these diols is also included.

\section{Biological production of $\mathrm{C} 3$ diols}

\subsection{1, 3-Propanediol}

1, 3-propanediol $(1,3-P D O)$ is a three-carbon glycol and a commodity chemical with efficient properties to be used as monomer in synthesis of plastics, polyesters, polyurethane, cosmetic preparations, pharmaceutical formulations, as plasticizer, in paints and adhesives. The major attention towards 1, 3-PDO production was started when a polyester polytrimethylene terephthalate was synthesized as a polycondensation product of 1, 3-PDO and terephthalic acid. Traditional chemical synthesis of 1,3-PDO involves hydration of acrolein, and hydroformylation of ethylene oxide. Both the chemical pathways involve expensive catalysts, harsh environmental conditions like high temperatures and pressure, still resulting in lower 1, 3-PDO titres and yield (Kaur et al., 2012; Maervoet et al., 2011; Pflügl et al., 2014; Vivek et al., 2016). Hence attention was diverted on to microbial biosynthesis.

\subsubsection{Microorganisms and physiology of 1, 3-PDO pathway}

Several microbes that are reported to produce 1, 3-PDO include the members of the genera Klebsiella, Clostridium, Lactobacillus, and Enterobacter (Kaur et al., 2012; Maervoet et al., 2011; Vivek et al., 2016). Among LAB species with GRAS status, Lactobacillus reuteri, Lactobacillus panis, and Lactobacillus diolivorans were reported for 1, 3-PDO production, whereas Lactobacillus diolivorans was industrially relevant strain producing high titres of 85 g/L 1, 3-PDO (Pflügl et al., 2014). Genetically modified strains with the ability to produce 1, 3-PDO by inserting the genes responsible for 1, 3-PDO metabolism in native strains, have 
many advantages, especially during the downstream processing. Genetically modified E. coli (Dabrowski et al., 2012; Yang et al., 2018), Clostridium beijerinckii (Wischral et al., 2016) are a few of the examples. Glycerol, a waste product from the biodiesel industry is utilized as the carbon source for 1, 3-PDO production (Figure 1). Glycerol is native substrate for 1, 3PDO production and metabolism of glycerol in native producers occurs in two different coupled oxidative and reductive pathways. The equilibrium in the coupled oxido-reductive pathway is essential to produce 1, 3-PDO and other by-products (Gungormusler et al., 2010). The production of 1, 3-PDO from glycerol occurs in the reductive pathway which acts as electron sink and consumes 1 mol NADH per mol of 1, 3-PDO generated. The reducing equivalents are obtained from the oxidative branch. The conversion of glycerol to 1, 3-PDO occurs in two steps. In the first step, adenosyl cobalamin (Vit $\mathrm{B}_{12}$ ) dependent glycerol dehydratase, GDHt removes a water molecule from glycerol to form 3-HPA. The reduction of 3-HPA to 1, 3-PDO is carried out by NADH-dependent enzyme 1, 3-propanediol dehydrogenase or 1, 3-propanediol-oxidoreductase (PDOR) (Vivek et al., 2016). ATP, $\mathrm{Mg}^{2+}$ and coenzyme $\mathrm{B}_{12}$ are required for the reactivation of GDHt as this enzyme gets inactivated by glycerol after every round of catalytic cycle. The genes encoding for the reactivating factors for glycerol dehydratase enzyme are $g d r A$ and $g d r B$ (Ma et al., 2010). Insertion of these genes into compatible hosts by making use of genetic engineering is carried out to increase the yield of 1, 3-PDO (Raynaud et al., 2011; Vivek et al., 2019).

\subsubsection{Spectrum of substrates}

Glycerol, a three-carbon compound with three hydroxyl functional groups with a highly reducing nature is metabolized in the biological system to produce 1, 3-PDO. In fermentations, product formation depends on the sources of carbon, nitrogen, energy, and hydrogen concentration (Drozdzyńska et al., 2011). Utilizing waste products from the biofuel industry is an efficient strategy in this scenario as the efficient utilization of cheap raw 
materials contributes towards the economization of the product. The economic and environmental aspects of utilizing glycerol as the substrate for the conversion to 1, 3-PDO has got attention from many researchers (Zhou et al., 2019). The potential 1, 3-PDO producers such as Citrobacter (Maervoet et al., 2011), Clostridium, Lactobacillus, Enterobacter, and Shimwellia (Rodriguez et al., 2016) can utilize glycerol as the carbon source. Production of 1, 3-PDO and n-butanol from glycerol by Clostridium pasteurianum DSM525 was tested by Moon et al. in 2011. Another major source used for the production is glucose as the carbon source. It contributes for biomass formation, NADH and ATP production. It is easily assimilated into the microbial cell compared to other carbon sources. The co-fermentation strategy opted for the increasing yield of 1, 3-PDO and it is discussed in the later section of this review. Lactobacillus reuteri and Lactobacillus brevis have the common oxidative pathway for the utilization of glucose and glycerol (Vivek et al., 2017; Vivek et al., 2016). L. diolivorans DSM14421 produced $73.7 \mathrm{~g} / \mathrm{L}$ of 1, 3-PDO when glucose and glycerol in equal concentration were added to the fermentation media as carbon sources (Pflügl et al., 2014).

Lignocellulosic biomass has been used as the co-substrate in the glycerol fermentation and support 1, 3- PDO formation. In an experiment carried out by Xin et al. in 2016, corn stover hydrolysate and glycerol were used as substrates (Xin et al., 2016). Inoculation of C. diolis DSM 15410 to the fermentation media containing the above substrates showed an increase of $31 \%$ yield by fed-batch mode of fermentation. $C$. beijerinckii DSM 791 utilized corn steep liquor as a replacement of yeast extract, a nitrogen source along with crude glycerol to produce 1, 3-PDO (Wischral et al., 2016).

\subsubsection{Genetic manipulations for improved 1, 3-PDO production}


Metabolic engineering of native producers of 1, 3-PDO by the overexpression of genes or the insertion of glycerol assimilation pathway to heterologous hosts is the genetic manipulations that were adopted till date. E. coli, S. cerevisiae, C. acetobutylicum are the majorly exploited microbes for heterologous expression. For many studies, genes from homologous and heterologous hosts are combined for the better utilization of the substrate to increase the yield (Celińska, 2010). Overexpression of gldA gene from E. coli encoding for glycerol dehydrogenase enzyme and $d h a K L M$ gene encoding for dihydroxyacetone kinase in $C$. beijerinckii DSM 791 strain improved the productivity by $26.8 \%-37.5 \%$. The increase in the growth rate of engineered strain was the reason for improved yield (Wischral et al., 2016). Dealing with the need for Vitamin $\mathrm{B}_{12}$ can be overcome by the heterologous expression of the vitamin $\mathrm{B}_{12}$ independent GDHt gene of Clostridium butyricum. The major industrial producer of 1, 3-PDO, DuPont and Genencor International, Inc. are using genetically modified $E$. coli which utilizes glucose as the carbon source by aerobic fermentation (Celińska, 2010). Cloning of $d h a$ operon to E. coli produced 8-9 g/L 1, 3-PDO from glycerol (Ma et al., 2010). In 2018, Yang et al. constructed E. coli JA11 strain with $13.47 \mathrm{~g} / \mathrm{L} \mathrm{1,} \mathrm{3-PDO.} \mathrm{This} \mathrm{was} \mathrm{the}$ first time where GAPDN pathway was introduced to a host to improve the production of 1, 3PDO for regeneration of $\mathrm{NAD}^{+}$along with modified transport system modification for better glycerol uptake. Insertion of gapN gene, encoding for the NADP+-dependent glyceraldehyde3-phosphate dehydrogenase pathway, was combined with specific 5'-untranslated regions for balancing the redox potential state to favors the 1,3-PDO production. The optimization of nitrogen sources was also carried out for better yield.

The S. cerevisiae W303-1A-BT strain with pZ-BT was constructed by Ma et al. in 2010. Incorporation of genes coding for GDHt along with its reactivating factor and PDOR from $K$. pneumoniae to heterologous host $S$. cerevisiae was done. The authors discuss the economically feasible operation by this strain for 1, 3-PDO production. Genetic modification 
in Pseudomonas denitrificans resulted in $68.95 \mathrm{mM} \mathrm{1,3-PDO}$ with the yield of $0.92 \mathrm{~mol} 1,3-$ PDO/mol glycerol by incorporating genes encoding for glycerol dehydratase and 1, 3-PDO oxidoreductase. This strain has the advantage of naturally synthesizing coenzyme $\mathrm{B}_{12}$ under aerobic condition which is an essential factor in 1, 3-PDO production. The deletion of the nuo operon and $n d h$ gene was carried out to facilitate $\mathrm{NADH}$ flow towards 1, 3-PDO oxidoreductase for the improved yield by unbalancing the redox balance in the electron transport chain (Zhou et al., 2019).

\subsubsection{Process modifications and optimization for improved 1, 3-PDO production}

In the production media, glucose is utilized for microbial growth and energy production, where glycerol is for the utilization of reducing equivalence. Even in the recombinant strains, glycerol glucose co-fermentation shows better yield than using glycerol as the sole carbon source. The co-fermentation strategy was carried out by most of the researchers to increase the yield. From a novel isolate, Lactobacillus brevis N1E9.3.3, Vivek et al. in 2016 were able to produce 1, 3-PDO with a yield of $0.89 \mathrm{~g} 1,3-\mathrm{PDO} / \mathrm{g}$ glycerol by anaerobic fermentation using co-fermentation strategy. The batch, sequential batch, and continuous modes of fermentation using the same above strain in suspended and immobilized cells were tested. In the batch mode of fermentation, $51.5 \mathrm{~g} / \mathrm{L}, 3-\mathrm{PDO} / \mathrm{L}$ and $42.59 \mathrm{~g} 1,3-\mathrm{PDO} / \mathrm{L}$ was observed using suspended and immobilized cells when the initial glucose: glycerol concentration or ratio was $80 \mathrm{~g} / \mathrm{L}$ with a $\mathrm{pH}$ of 8.5 and temperature $37^{\circ} \mathrm{C}$ under anaerobic condition. In the repeated batch mode of fermentation, $78.3 \mathrm{~g} / \mathrm{L} 1,3-\mathrm{PDO}$ was obtained at the $5^{\text {th }}$ cycle using the cells immobilized on polyurethane foam (Vivek et al., 2017).

Conversion of glycerol to 1, 3-PDO catalysed by Shimwellia blattae ATCC 33430 resulted in 1, 3-propanediol formation with a concentration of $13.84 \mathrm{~g} / \mathrm{L}$ and yield of $0.45 \mathrm{~g} / \mathrm{g}$ (Rodriguez et al., 2016). Using mixed cultures for fermentation is another strategy employed 
by many researchers. Veras et al. in 2019 used biofilm fixed on silicone support in the UASB reactor for 1, 3-PDO conversion from glycerol. The productivity was closer to $7.5 \mathrm{~g} / \mathrm{L} / \mathrm{d}$ while crude and pure glycerol was given as the substrate. Clostridium, Lactobacillus sp. was the major groups present in the biofilm for the conversion. Mixed microbial consortia under different operation conditions were able to produce a consistent pattern for 1, 3-PDO production from glycerol in an experiment conducted by Zhou et al. in 2018 with a maximum production of $57.86 \mathrm{~g} / \mathrm{L} \mathrm{1,3-PDO}$. Expanded granular sludge blanket reactors operated in anaerobic mode inoculating with granular sludge converted glycerol to 1, 3-PDO with a productivity of $57 \mathrm{~g} \mathrm{~L}^{-1} \mathrm{~d}^{-1}$ (Gallardo et al., 2014).

\subsection{1, 2-Propanediol}

1, 2-propanediol or propylene glycol $\left(\mathrm{C}_{3} \mathrm{H}_{8} \mathrm{O}_{2}\right)$ is a colorless liquid compound with one asymmetrical carbon atom resulting in two isomeric forms $(\mathrm{R})$ and $(\mathrm{S})$-1, 2-propanediol, and commercially available as a racemic mixture (Niu et al., 2019; Zhang et al., 2017). As a commodity chemical 1, 2-PDO has immense potential in the global market about 3332.2 million USD in 2020 and expected to be around 3968.7 million USD by 2025 with a CAGR of $2.5 \%$. Currently, the market demand of 1, 2-PDO is met by chemical synthesis, through the following methods; hydrogenolysis of sugars, hydration of propylene oxide either by chlorohydrin or hyperoxide process, hydrogenation of lactate esters, and reduction of acetol. The key players of 1, 2-PDO manufacturers are Dow, LyondellBasell, Huntsman, INEOS, BASF, ADM, and Shell, etc. The chemical is used as a building block in the synthesis of antifreeze or engine cooling agents, solvents, plasticizers, detergents, cosmetics, the unsaturated polyester resin used as coatings, glass reinforcements, and an intermediate for the synthesis of active pharmaceutical ingredients (Niu et al., 2019; Zhang et al., 2017).

\subsubsection{Microorganisms and physiology of 1, 2-PDO pathway.}


Currently genetically modified E. coli strains were reported to produce high titres of $1,2-$ PDO, the first report of bacteria Clostridium thermobutyricum producing the metabolite is dated back to 1954 (Enebo 1954). Later, yeast strains of genera Debaryomyces, Pichia, Candida, and Torulopsis were observed to assimilate 1, 2-PDO from L-rhamnose (Suzuki and Onishi, 1968; Tran-Din, 1985). Recently on the quest for finding enzymes for better catalytic efficiency through genome mining tools or the knowledge of whole-genome analysis led to finding of various other strains of genera Clostridium (Huang et al., 1999; Tran-Din, 1985), Thermoanaerobacterium (Altaras, 2001), Corynebacterium (Niimi et al., 2011), Caldicellulosiruptor (Ingvadottir et al., 2017), and Cyanobacteria (Li and Liao, 2013) that can produce 1, 2-PDO from different sugar substrates.

The initial biosynthesis pathway identified for the production of 1, 2-PDO is from two deoxysugars L-fucose and L-rhamnose in Clostridium thermosaccharolyticum. In this pathway, the two deoxysugars are converted to lactaldehyde in three consecutive reactions mediated by isomerase, kinase, and aldolase, later the lactaldehyde is reduced to 1,2-PDO by alcohol dehydrogenase (Figure 2)(Suzuki and Onishi, 1968; Tran-Din, 1985; Ingvadottir et al., 2017; Fjölnisdóttir et al., 2018). Although the metabolic pathway is well characterized, the commercial-scale synthesis from deoxysugars is not feasible, due to the limited availability of the substrates and their cost. Hence a search for an economically feasible process led to the most reliable methylglyoxal (MG) reduction pathway. In the MG pathway, dihydroxyacetone phosphate, intermediate of glycolytic pathway, is converted to MG by MG synthase $(m g s A)$, and further conversion can be either through (i) formation of acetol from MG by alcohol dehydrogenase (fucO/yqhd) and further reduction by glycerol dehydrogenase ( $g l d A$ ) to yield 1, 2-PDO or (ii) formation of lactaldehyde by glycerol dehydrogenase ( $\mathrm{gldA}$ ) from MG and later reduced to 1, 2-PDO by an alcohol dehydrogenase (fucO/yqhd) (figure). The advantages of this MG pathway is broad spectrum of substrates from renewable 
feedstocks (C6 and C5 sugars), biodiesel derived crude glycerol, and $\mathrm{CO}_{2}$, can be used via alternative routes (Altaras, 2001).

Later in 2001, Elferink and associates observed that in an anoxic condition and acidic environment, lactic acid bacterial strains convert $1 \mathrm{~mol}$ of lactic acid into $0.5 \mathrm{~mol}$ acetate and 0.5 mol 1, 2-propanediol; with this observation a novel lactic acid-mediated pathway was proposed. In this pathway, lactic acid is converted to lactaldehyde via lactoyl-CoA by acylating aldehyde dehydrogenase and later reduced to 1, 2-PDO by alcohol dehydrogenase (fucOlyqhd). The major advantage of the pathway is bypassing the toxic intermediates like MG in the previous pathway and as LAB strains are considered GRAS and can easily cultivate under acidic conditions.

\subsubsection{Genetic manipulations for improved 1, 2-PDO production}

Although various native 1, 2-PDO producers are isolated which can metabolize different spectrum of renewable feedstocks (C5 and C6 sugars) (Altaras, 2001), biodiesel derived crude glycerol (Lee et al., 2016) and $\mathrm{CO}_{2}$ ( $\mathrm{Li}$ and Liao, 2013) via alternative biosynthetic pathways, but there are few limitations and challenges that are limiting the processes to be commercialized. In this section, we discuss only the biosynthetic pathway from sugars, glycerol, and $\mathrm{CO}_{2}$ as deoxysugars mediated pathway is straight forward and is not economical. How to address these challenges? The answer would be genetic engineering. So,

what are these limitations and challenges, (i) Similar to 1, 3-propanediol biosynthesis, 1, 2PDO is a reductive process in which the enzymes mediating the reaction are cofactor $[\mathrm{NAD}(\mathrm{P}) \mathrm{H}]$ dependent, hence the continuous supply of these reducing equivalents which is necessary for smooth production, impacts product titres and yield, (ii) accumulation of toxic intermediates like MG and lactaldehyde, and (iii) accumulation of toxic by-products (Bennett and San, 2001; Saxena et al., 2010; Zhang et al., 2017). 
To increase the availability of reducing equivalents to produce 1, 2-PDO (2 moles NADH per mole 1, 2-PDO), and the competing pathways should be inhibited, and carbon flux should be directed towards MG or lactate-based pathway. An E. coli culture as the chassis strain, Jain, and associates modified the central carbon metabolism wherein the majority of the sugar was directed to glycolysis by deleting the pentose phosphate pathway to generate more DHAP. As DHAP is required to produce MG, further by-product producing genes like glucose-6phosphate dehydrogenase (zwf) triphosphate isomerase (tpiA), lactate dehydrogenase (ldhA), and alcohol dehydrogenase $(a d h E)$ were deleted to reduce the concentrations of glyceraldehyde 3 -phosphate, lactate $(0.14 \mathrm{~g} / \mathrm{L})$, succinate $(0.22 \mathrm{~g} / \mathrm{L})$, formate $(0.33 \mathrm{~g} / \mathrm{L})$, acetate $(0.65 \mathrm{~g} / \mathrm{L})$ and ethanol $(0.05 \mathrm{~g} / \mathrm{L})$. As per the objective, NADH availability increased, unexpectedly 1, 2-PDO concentration was reduced to $0.35 \mathrm{~g} / \mathrm{L}$, the low titres of product is due to reduced glucose uptake rate $(1.64 \mathrm{~g} / \mathrm{L}$ vs $11.75 \mathrm{~g} / \mathrm{L})$ compared to wild type (Jain et al., 2015). It is well known that formate dehydrogenase overexpression is the best strategy to increase the availability of reducing equivalents as the enzyme regenerate $\mathrm{NAD}(\mathrm{P})^{+}$ions. Overexpression of formate dehydrogenase in engineered $E$. coli strain along with adaptive laboratory evolution, increased the glucose uptake rate $(5.35 \mathrm{~g} / \mathrm{L} \mathrm{Vs} 1.75 \mathrm{~g} / \mathrm{L})$ and resulted in $5.13 \mathrm{~g} / \mathrm{L}$ 1, 2-PDO with $0.48 \mathrm{~g}$ 1, 2-PDO/g Glucose yield (Jain et al., 2015). Similarly, Corynebacterium glutamicum was engineered to decrease the regulation of oxidative phosphorylation, as most of the NADH molecules are oxidized via oxidative phosphorylation, and later overexpressed with MG synthase $(m g s A)$, glycerol dehydrogenase (gldA), and alcohol dehydrogenase (yqhd) from E. coli strain. In aerobic fermentation of glucose, the modified metabolically engineered strain was able to produce $4.8 \mathrm{~g} / \mathrm{L} 1,2-\mathrm{PDO}$ with $0.15 \mathrm{~g} \mathrm{1,2-PDO/g}$ Glucose yield (Niimi et al., 2011). In the MG pathway, MG and lactaldehyde are the toxic intermediates that do interfere in the growth and development of the chassis strain. Therefore, to increase the end-product titres, the employed strategies 
should reduce the MG accumulation. Recently a technique was developed to perform multiple reaction mechanisms or novel mechanisms using fused enzymes. These fused enzymes do catalyze series of reactions so that the availability time of intermediates in the surrounding medium decreases. By employing this strategy in 1, 2-PDO production, the specific activity of the enzymes increased up to 3.5 times (Sabra et al., 2016; Zeng, 2019; Zeng and Sabra, 2011a). Another major discovery to reduce MG concentrations in the fermentation medium is MG independent pathway in lactic acid bacterial cultures. An E. coli K12 MG 1655 homolactic fermentative strain was used to express MG independent pathway where the flux of carbon is towards lactic acid, and to prevent the back flux, two membraneassociated lactate dehydrogenase genes ( $d l d$ and $l l d D)$ were deleted. In biocatalysis, the basic advantage is the stereospecificity of the final product and to ensure that the final product is not a racemic mixture, the gene involved in racemisation MG synthase ( $m g s A)$ was deleted. Later in the resulting strain, propynyl CoA acylating dehydrogenase $(P d u P)$ from Salmonella enterica, CoA transferase $(p c t)$, and lactaldehyde reductase $(y q h k)$ were overexpressed to produce $17.3 \mathrm{~g} / \mathrm{L}(\mathrm{R})-1,2-\mathrm{PDO}$ and $9.3 \mathrm{~g} / \mathrm{L}(\mathrm{S})-1,2-\mathrm{PDO}$ with 0.42 and $0.23 \mathrm{~g} 1$, 2PDO/glactate yield with D and L lactic acid respectively (Niu et al., 2019). The propynyl CoA acylating dehydrogenase $(P d u P)$ mediates a rate-limiting reaction in which lactoyl CoA is converted to lactaldehyde, the enzyme has higher specific activity and specificity to lactoyl CoA than other enzymes: sulfoacetyl CoA acylating dehydrogenase (SauS) from Cupriavidus necator and succinyl CoA acylating dehydrogenase $(S u c D)$ from Clostridium kluyveri (Niu and Guo, 2015).

Saccharomyces cerevisiae is a conventional yeast strain, and well known eukaryotic expression system along with Pichia pastoris. S. cerevisiae has higher glucose uptake rate and galactose utilization efficiency compared to other strains, but lack the pathway for the production of 1, 2-PDO, it was observed that growth of yeast in the complex media detected 
traces of 1, 2-PDO in high-performance liquid chromatography (Bennett and San, 2001). When a heterologous MG pathway; MG synthetase ( $m g s A)$ gene from E. coli MG1655 and glycerol dehydrogenase (dhaD) gene from Citrobacter freundii was expressed in $S$. cerevisiae, it resulted in $0.45 \mathrm{~g} / \mathrm{L} \mathrm{1,} \mathrm{2-PDO} \mathrm{from} \mathrm{galactose} \mathrm{as} \mathrm{sole} \mathrm{carbon} \mathrm{source} \mathrm{(Jeon} \mathrm{et} \mathrm{al.,}$ 2009). Later the work was carried out by Islam and associates to engineer $S$. cerevisiae by introducing DHA (NAD+ glycerol dehydrogenase from Ogataea parapolymorpha (opgdh)) pathway by replacing native FAD-dependent glycerol catabolic pathway and deleting glycerol kinase $(G U T 1)$. In this study, the rate of glycerol uptake was increased by expressing a glycerol facilitator from Cyberlindnera jadinii (CjFPS1) along with a native glycerol symporter (STL1). The mutant yeast strain with increased glycerol uptake, increased NADH and DHAP availability for MG biosynthesis resulted in > $4 \mathrm{~g} / \mathrm{L} \mathrm{1,} \mathrm{2-PDO} \mathrm{(Islam} \mathrm{et} \mathrm{al.,} \mathrm{2017).}$ Further, in an environmentally friendly approach Synechococcus elongatus PCC 7942 was engineered with heterologous MG pathway from E. coli resulted in $22 \mathrm{mg} / \mathrm{L} \mathrm{1,} \mathrm{2-PDO} \mathrm{using}$ $\mathrm{CO}_{2}$ as the sole carbon source, later taking the advantage of NADPH pool in cyanobacteria. Further improvement was achieved with overexpression of NADPH dependent alcohol dehydrogenase which yielded150 mg/L 1, 2-PDO (Li and Liao, 2013). But it was observed that the only $3 / 4^{\text {th }}$ of carbon in $1,2-\mathrm{PDO}$ was from $\mathrm{CO}_{2}$ and another $1 / 4^{\text {th }}$ was from glycogen, the storage energy for cyanobacteria. The homology modelling also predicted the presence of genes encoding the MG pathway in cyanobacteria (David et al., 2019).

Research on propanediol has been very important resulting in the synthesis of reliable polymer polytrimethylene terephthalate from 1, 3-propanediol and terephthalic acid, but the genetics and physiology of the pathway discovered that the genes responsible for the assimilation and dissimilation are existing in a compartment inside the microbial cell and are called as bacterial microcompartments (BMCs). In E. coli CFT073 glycyl radical microcompartments are have been discovered with propanediol dissimilating genes. These 
BMCs are protein-based organelles confined for the pathways with toxic intermediates and volatile compounds, which are fatal for the microbial cell (Lundin et al., 2020; Nichols et al., 2020; Plegaria et al., 2017). So these BMCs could be ideal sites for the MG pathway as the intermediates do not interfere with the central carbon metabolism of the host strain, Matthew Lee and associates tagged the enzymes glycerol dehydrogenase, dihydroxyacetone kinase, MG synthase, and 1, 2-PDO oxidoreductase for localization into empty inclusion bodies or BMCs in a fused fashion, the resulting strain could produce $12 \mathrm{mM} \mathrm{1,2-PDO}$ per O.D 600 , which is equivalent to $245 \%$ increase in the product titres (Lee et al., 2016).

\subsubsection{Process modifications and optimization for improved 1, 2-PDO production}

Fermentative production of 1, 2-PDO from L-rhamnose, L-fucose, pure sugars, or pure glycerol will not be economical. The highest 1, 2-PDO titre reported in 1987 was by wild type Clostridium thermosaccharolyticum; $9.1 \mathrm{~g} / \mathrm{L}$ with a yield of $0.2 \mathrm{~g} / \mathrm{g}$ and a productivity of $0.35 \mathrm{~g} / \mathrm{L} / \mathrm{h}$. The strain was also observed to utilize either D-glucose or D-xylose to produce (R)-1,2-PDO (Sánchez-Riera et al., 1987). Later, genetic engineering strategies were employed in developing a chassis strain which resulted in the highest titre up to $18 \mathrm{~g} / \mathrm{L}$, but still an attractive low-cost substrate is required for commercial-scale production. It was reported that $T$. thermosaccharolyticum $\mathrm{HG}-8$ strain able to utilize a wide spectrum of substrates that can be obtained from renewable feedstocks to produce 1, 2-PDO (Altaras, 2001). With the increase in demand for biodiesel, it is surplus by-product crude glycerol is also an attractive source for the production of value-added products. As Lee et al., 2016 developed a chassis strain that could utilize glycerol for 1, 2-PDO production; further studies on process engineering, optimization of media parameters using crude glycerol would be beneficial to understand the efficiency of the strain. In 1, 2-PDO production, environmental and physiological factors like temperature, $\mathrm{pH}$, substrate concentrations, and gas phase 
composition have significant influence. In a study using $C$. thermosaccharolyticum, as an obligate anaerobic and mesophilic bacterium, the optimum conditions like $60^{\circ} \mathrm{C}, \mathrm{pH}-6.0$, and nitrogen atmosphere resulted in increased 1, 2-PDO titres (Sánchez-Riera et al., 1987). Along with physiological conditions, media components do influence the product titres, it was observed that under phosphate limitation $(<80 \mu \mathrm{M})$ Clostridium sphenoides was able to produce 1, 2-PDO along with other organic acids, $\mathrm{H}_{2}$ and $\mathrm{CO}_{2}$. However, triggering mechanism of phosphate limitation towards 1, 2-PDO was not observed in C. glycolicum, C. nexile, C. oxaticum and C. indolis (Tran-Din, 1985). Similarly, as the cyanobacterial cells could not synthesize 1, 2-PDO when stored glycogen is depleted, supplementation of the glycogen increased the product titres up to $1.0 \mathrm{~g} / \mathrm{L}$ (David et al., 2018). To date, research is mostly concentrated on constructing a chassis strain either through homologous or heterologous gene expressions for synthetic pathways, but the product titres and yields are quite low for commercialization. Further research on system engineering, culture conditions, and process development could result in increased 1, 2-PDO titres, yield, and productivity.

\section{Biological production of $\mathrm{C} 4$ diols}

\subsection{2, 3-Butanediol}

2, 3-Butanediol (2, 3-BDO) is such a platform chemical currently produced petrochemically and have diverse application in the field of agriculture, pharmaceutical and food industry. It also have end application in the manufacture of solvents, fumigants, cosmetics and synthetic rubber (Ji et al., 2011). 2, 3-BDO can be used as a fuel additive with aviation fuels, because of its high heat of combustion $\left(27.2 \mathrm{~kJ} \mathrm{~g}^{-1}\right)$, similar to other liquid fuels such as methanol

$\left(22.1 \mathrm{~kJ} \mathrm{~g}^{-1}\right)$ and ethanol $\left(29.1 \mathrm{~kJ} \mathrm{~g}^{-1}\right)$. Estimated annual global market value for 2, 3-BDO derivatives itself is 43 billion dollars (Köpke et al., 2011). 
2, 3-BDO exists in 3 isomeric forms; meso, dextro and leavo forms. Meso and L forms are used as building blocks for the synthesis of chiral compounds. Enantiopure D(R, R) BDO is a used as an antifreeze agent because of its very low freezing point (Gaspar et al., 2011). 2, 3BDO produced by certain root associated bacteria (rhizobacteria) elicits induced systemic resistance in plants. A study shows when pepper plant roots were inoculated with Bacillus subtilis strain; rhizosphere colonization by saprophytic fungi was found to be declined from 14 days after inoculation. BDO thus triggers the secretion of root exudates that modulate systemic resistance in plants (Yi et al., 2016).

\subsubsection{Microorganisms and physiology of 2, 3-BDO pathway in native and non-native producers}

Conventional petrochemical route for 2, 3-BDO is energy intensive and use harsh chemicals and conditions, thus environmentally unsound. But the microbial production of 2, 3-BDO via fermentation is quite sustainable and safe since it doesn't produce any hazardous chemicals during its process. Klebsiella pneumoniae, Klebsiella oxytoca, Serratia marcescens, Enterobacter aerogenes, Bacillus licheniformis, Bacillus amyloliquefaciens, Paenibacillus polymyxa are some of the well-known microorganisms reported for 2, 3-BDO fermentation. Saccharomyces cerevisiae (Kim and Hahn, 2015)and Escherichia coli are well studied as heterologous hosts for 2, 3-BDO production.

The exact mechanism why bacterial cells adapt 2, 3-BDO fermentation pathway is not clear till now. Still it has been hypothesized that to prevent intracellular acidification, and to balance NAD+-NADH ratio inside the cell and as a measure of carbon and energy storage. Two molecules of pyruvate undergo self-condensation to form $\alpha$-acetolactate by the enzyme acetolactate synthase (ALS). $\alpha$-acetolactate readily oxidise to diacetyl in presence of oxygen. Diacetyl reductase enzyme converts diacetyl to acetoin. In an alternative route, $\alpha$-acetolactate is decarboxylated to acetoin by the enzyme acetolactate decarboxylase followed by reduction 
of acetoin to 2, 3-BDO mediated through acetoin reductase/BDO dehydrogenase (Figure 3). The concentration of acetoin and 2, 3-BDO determines the direction of reaction.

Klebsiella and Enterobacter species require very simple media and growth conditions for 2, 3-BDO production. But World Health Organization (WHO) classified these organisms as Risk 2 level (Lee and Seo, 2019). So the applicability of such opportunistic pathogens in the field of an industrial bioprocess has become limited. Jung et al., 2013 reported that removal of virulence factor wabG leads to a negative impact on productivity. Along with pathogenicity, possibility of bacteriophage infection is also considered while selecting a suitable organism for an industrial bioprocess.

\subsubsection{Spectrum of substrates}

Hexose, pentoses and disaccharides can serve as the substrate for 2, 3-BDO fermentation via mixed acid fermentation pathway. Substrate cost is one of the major limiting factors in an industrial bioprocess. Other than glucose or xylose bacteria could utilize sugars from renewable plant biomass such as sugarcane bagasse, sugar beet molasses, wood hydrolysate, dairy industry wastes, Jerusalem artichoke tubers, water hyacinth, food industry wastes, biodiesel derived crude glycerol and some other softwood (Cho et al., 2015a, 2015b; Choi et al., 2016; Erian et al., 2018; Fages et al., 1986; Grover et al., 1990; Motwani et al., 1993; Perego et al., 2000). It is possible to use a low cost, readily available waste biomass as the substrate for 2, 3-BDO fermentation. P. polymyxa secrets inulinase enzymes which could utilize the inulin in non-grain materials such as J. artichoke tubers and other biomass, thus reducing the enzyme hydrolysis costs (Häßler et al., 2012).

The carbon and nitrogen sources, aeration, $\mathrm{pH}$ and temperature are the important factors that influence the growth of bacteria and product formation in 2, 3-BDO fermentation. Bacillus licheniformis strain X10 could efficiently utilize the sugars from corn stover hydrolysate and 
produced 74.0g/L 2, 3-BDO in fed batch fermentation. The strain simultaneously use glucose and xylose in the hydrolysate without carbon catabolite repression ( $\mathrm{Li}$ et al., 2014).

\subsubsection{Genetic manipulations for improved 2, 3-BDO production}

Genetic manipulation aims to eliminate the formation of other metabolites of mixed acid pathway and redirecting the pyruvate flux specifically to 2, 3-BDO. Moreover, advanced tools in recombinant technology focused on making the microorganism efficiently utilize the sugars in lignocellulose biomaterials for fermentation.

The Bacillus subtilis strain produce (D)-BDO under low oxygen concentrations. In B. subtilis $b d h A, a c o A$ genes were knocked out to prevent the degradation of acetoin, budC gene from Klebsiella pneumoniae was introduced and alsS was overexpressed. The pool of NADH availability was increased to facilitate the conversion of meso 2, 3-BDO from acetoin by overexpressing $u d h A$ which is a soluble transhydrogenase and low oxygen was maintained during the cultivation. The best strain BSF9 resulted in producing $103.7 \mathrm{~g} / \mathrm{L}$ of meso 2, 3BDO with $0.48 \mathrm{~g} / \mathrm{g}$ of glucose yield. The major by-product of 2, 3-BDO pathway is acetoin and it was found to present in very lesser amount (Fu et al., 2016).

Bacillus amyloliquefaciens $\mathrm{B} 10-127$ produced $92.3 \mathrm{~g} / \mathrm{L}$ total 2, 3-BDO with a productivity of $0.96 \mathrm{~g} / \mathrm{L} / \mathrm{h}$ ( Yang et al., 2013). It has been reported that Bacillus species does not produce any ethanol or other acids in significant amount thus efficient carbon utilization could be achieved. The genetic information of B. amyloliquefaciens has well studied and provides the possibility of genetic manipulation for improved productivity. The overexpression of glyceraldehydes 3-phosphate dehydrogenase $(G A D P H)$ resulted in an increased level of NADH pool and lower level of NAD+. Butanediol dehydrogenase $(b d h)$ catalyses the conversion of acetoin to 2, 3-BDO with concomitant oxidation of $\mathrm{NADH}$ to $\mathrm{NAD}^{+}$. The overexpression of $b d h$ gene resulted in low levels of NADH pool and increased level of $\mathrm{NAD}^{+}$, finally, $132.9 \mathrm{~g} / \mathrm{L} \mathrm{2}$, 3-BDO was achieved with a productivity of $2.95 \mathrm{~g} / \mathrm{L} / \mathrm{h}$. Another 
important Bacillus spp.FJ4 reported produced $>99.9 \%$ enantiopure D (-) 2, 3-BDO and produced 100g/L 2,3-BDO from 226.8g/L glucose with a 0.44g/g yield (Yan et al., 2017).

Paenibacillus polymyxa is important because of its ability to produce optically pure R, RBDO while growing in anaerobic conditions (Okonkwo et al., n.d.). It also secrets inulinase enzyme that could utilize the inulin in J. artichoke tubers, another lignocellulosic biomass, thus reducing the enzyme hydrolysis costs. $P$. polymyxa ZJ-9 produced ultra-high pure $>99.99 \% \mathrm{R}, \mathrm{R}-\mathrm{BDO}$ by deletion of diacetyl reductase gene $(d u d A)$ by homologous recombination (Akhtar, 2007).

Saccharomyces cerevisiae used for industrial applications use a wide range of substrates with GRAS status (Generally Recognized as Safe). S. cerevisiae exhibit faster growth rate, high tolerance against sugars, inhibitors and other alcohols. S. cerevisiae lacks $\alpha$-acetolactate decarboxylase which catalyses the direct conversion of acetoin from alpha-acetolactate. $\alpha$ acetolactate, produced by $\alpha$-acetolactate synthase (Ilv2) in mitochondria, is converted to acetoin via diacetyl formation. Industrial polyploid S. cerevisiae has so many advantages, but genetic manipulations might not be as easy as expected. alsS, alsD genes from B. subtilis with over-expressed endogenous $B D H 1$ were used. Pyruvate decarboxylase $(p d c)$, alcohol dehydrogenase $(A D H)$ genes were disrupted and grown with glucose as the sole carbon source without supplementation of $\mathrm{C} 2$ compound. NADH oxidase system (nox $E$ ) has been introduced at the ADH1 disruption site. While using a glucose based YP medium, $178 \mathrm{~g} / \mathrm{L} 2$, 3-BDO with a maximum productivity of $2.64 \mathrm{~g} / \mathrm{L} / \mathrm{h}$ was achieved observed in a fed-batch fermentation (Choi et al., 2016; Kim and Hahn, 2015; Kim et al., 2017).

Lactococcus lactis is a homofermentative bacterium widely used in the manufacture of dairy products. It has GRAS status and one among best studied species in lactic acid bacteria. It is a model organism for metabolic engineering strategies for industrial bioprocesses because of its comparatively smaller genome. Gasper and co-workers deleted the lactate dehydrogenase 
$(l d h)$ and alcohol dehydrogenase $(a d h E)$ genes and overexpressed the acetolactate synthase $(a l s A)$ and acetoin reductase (but $A$ ) genes under the control of nisin promoter. It is found to be effective in utilizing whey permeate as a substrate for 2, 3-BDO production (Gaspar et al., 2011). .

\subsubsection{Process modifications and optimization for improved 2,3-BDO production}

Other than batch fermentation, fed batch and cell immobilization strategies were attempted to improve yields (Martinez and Speckman, 1988). Along with genetic modification of the strain physical parameters and culture conditions have profound effect on the final product concentration.

\subsubsection{Effect of carbon and nitrogen sources}

Since 2, 3-BDO fermentation is a cellular mechanism for storage of carbon and energy sources, increased carbon sources have a positive effect on fermentation. But increasing substrate concentration may not be beneficiary for microbial growth. Substrate inhibition is one of the major problem significantly affecting industrial bioprocesses (Jung et al., 2015).

High cost of nitrogen sources was not feasible for 2, 3-BDO fermentation in an economic view. Locally available and low cost nitrogen sources such as corn steep liquor have been successfully demonstrated ( Yang et al., 2013).

\subsubsection{2. $\quad$ Effect of temperature}

Temperature is an important factor in a bioprocess because of the strong dependence of enzymatic activity and cellular maintenance. The optimum temperature spectrum for 2, 3BDO fermentation is from $30-37^{\circ} \mathrm{C}$ (Okonkwo et al., n.d.). The thermophilic microorganisms have also been reported for 2, 3-BDO production (Ge et al., 2016).

\subsubsection{3. $\quad$ Effect of $\mathbf{p H}$}


Generally, a $\mathrm{pH}$ range of 6.0-7.5 has been observed as an optimum for 2, 3-BDO fermentation. But acidic environment favors 2, 3-BDO formation which may not be effective for microbial growth. Strategies like deliberate addition of acids for bringing down the $\mathrm{pH}$ to acidic conditions was attempted and successfully increase in 2, 3-BDO production was noticed (Nakashimada et al., 2000). Addition of acetic acid results in an environment similar to intracellular acidification and positively affecting on 2, 3-BDO production.

\subsubsection{Dissolved oxygen}

Dissolved oxygen has been shown to have a profound effect on product distribution. Acetoin was found to produce in a dissolved oxygen level >100ppb. 2, 3-BDO was secreted in the media at a dissolved oxygen concentration less than 100ppb. Expression of alsS and alD was increased under anaerobic condition compared with aerobic condition. But increased agitation positively affecting the final 2, 3-BDO titres (Cho et al., 2015b).

Compared to other alcohols, industrial fermentative production of 2, 3-BDO is important and efficient because of high volumetric productivities and the lower inhibitory effect. The bioprocesses have the potential applicability to be scaled up to an industrial scale by integrating with current commercially successful biorefineries. Substrate inhibition is one of the major challenges similar to any other product derived from biomass. Presence of fermentation inhibitors such as furfural, vanillin, acetic acid and formic acid are the major reason behind this. Overall yield and enantiopurity of the final product are the major factors should be considered. The strong hydrophilic nature of 2, 3-BDO makes its downstream processing as a tedious task. Selection of a suitable downstream processing is an important criterion to be considered during bioprocess for 2, 3-BDO.

\subsection{1, 4-Butanediol}


1, 4-butanediol (1, 4-BDO) is an important commodity chemical used in the synthesis of plastics, polyurethane, elastic fibers, and other intermediate chemicals. Of their applications, the most important is the production of $\gamma$-butyrolactone, tetrahydrofuran, and polybutylene terephthalate (PBT). THF is produced by an acid-catalyzed dehydration reaction. THF is heterocyclic organic ether, miscible in aqueous solutions, and the primary application is to synthesize elastomeric polyurethanes called as Spandex, and used in the production of resins, solvents, and inks. PBT is an engineered thermoplastic with excellent physical, mechanical, and biodegradable properties. 1, 4-BDO is produced from the condensation of petroleum feedstocks like acetylene and formaldehyde, the process is developed by Walter Reppe and named as the Reppe process. Later various chemical processes like hydrogenation of maleic anhydride, isomerization of propylene oxide, acetoxylation of butadiene were developed to meet the global market demand (Burgard et al., 2016; Sabra et al., 2016; Silva, 2020; Satam et al., 2019).

\subsubsection{Microorganisms and physiology of 1, 4-BDO pathway.}

Though 1, 4-BDO has superior applications; the chemical is non-natural as there is no existing native biosynthetic pathway to produce $1,4-\mathrm{BDO}$ from any pure sugars or renewable feedstock. But the advanced systems biology and synthetic biology approaches led to engineering a biosynthetic pathway using prediction tools and genetic algorithms in E. coli. Genomatica Inc. has patented a technology GENO-BDO ${ }^{\mathrm{TM}}$ in which the non-natural pathway for 1, 4-BDO production was expressed in E. coli strains. The engineered strain could utilize a different spectrum of pure sugars and sugars derived from lignocellulosic biomass. The process engineers and molecular biologists of Genomatica Inc., in January 2009, after a tremendous effort developed a non-natural pathway consisting of six heterologous steps in which an intermediate of tricarboxylic acid (TCA) cycle, succinyl-CoA is converted to 1, 4- 
BDO. In this pathway, succinate semialdehyde dehydrogenase $(S u c D)$ mediates the conversion of succinyl-CoA to succinyl semialdehyde and then reduced to 4-hydroxy butyrate (4-HB) by 4-hydroxybutyrate dehydrogenase $(4 h b d)$. Further 4-HB is reduced to 1,4-BDO by CoA transferase (Cat2), aldehyde dehydrogenase, and alcohol dehydrogenase (Figure 3)(Wu et al., 2016; Sabra et al., 2016; Burgard et al., 2016; Sabra et al., 2016; Zeng and Sabra, 2011b). The E. coli strain expressing the heterologous pathway produced $\sim 18 \mathrm{~g} / \mathrm{L}$ 1, 4-BDO, but the titres and the yield obtained is not commercially viable.

If genetic modification also increases the spectrum of substrates, the process can be sustainable, where renewable feedstocks can be utilized by reducing the final cost of the process. The fermentable sugars obtained from renewable feedstocks are mostly; glucose, xylose, arabinose, and galactose, Liu and his associate developed a novel pathway in which xylose is converted to $1,4-\mathrm{BDO}$, and the co-substrates or other carbon sources are used for growth and development. In this pathway xylose is converted to xylonic acid in the presence of xylose dehydrogenase ( $x d h$ from $C$. crescentus), then xylonic acid dehydratase (yjhG or yagF from E. coli), and 2-dehydro-3-deoxy-D-xylonate dehydratase (xylX or hvo from $C$. crescentus and $H$. volcanii), converts xylonic acid into $\alpha$-ketoglutaric semialdehyde, followed by reduction to $1,4-\mathrm{BDO}$ by semialdehyde dehydrogenase (sadh), alcohol dehydrogenase (adh), ketoacid decarboxylase (mdIC or kivD from P. putida and L. lactis) (Liu and Lu, 2015).

It was observed that the enzymes required to control the carbon flux towards 1, 4-BDO production from glucose can be divided into three groups, glycolytic enzymes + upper branch of TCA cycle, the lower branch of TCA cycle, and the non-natural BDO pathway, in which lower TCA cycle is important as it provides the precursor succinyl-CoA for the BDO production (Andreozzi et al., 2016). To commercialize the bioprocess for 1, 4-BDO production, the main challenges to be addressed are; (i) specific activity of the upstream and 
downstream enzymes, (ii) cofactor availability, as 4 moles of $\mathrm{NAD}(\mathrm{P}) \mathrm{H}$ is required to produce 1 mol 1, 4-BDO from glucose, (iii) preventing by-product or intermediates mediated inhibition, and (iv) avoiding expensive antibiotics in the commercial scale.

\subsubsection{Genetic manipulations for improved 1, 4-BDO production}

Rewiring the central carbon metabolism, the availability of reducing equivalents and energy currency towards 1, 4-BDO production in E. coli, triggered the modified strain to produce $18 \mathrm{~g} / \mathrm{L}$, but metabolite analysis quantified the accumulation of large amounts of pyruvate, acetate, and $\mathrm{CO}_{2}$. To eliminate the production of $\mathrm{CO}_{2}$, the endogenous genes sad and gabD which codes for succinate semialdehyde dehydrogenase were deleted, the resulting strain could produce $\sim 29 \mathrm{~g} / \mathrm{L} 1,4-\mathrm{BDO}$. To prevent the use of antibiotics and to deal with plasmid instability and consistency of the engineered strain, integration of the 1, 4-BDO pathway genes into chromosome under the expression of constitutive promoters resulted in $\sim 90 \mathrm{~g} / \mathrm{L} 1$, 4-BDO with yield and productivity of $0.35 \mathrm{~g} / \mathrm{g}$ and $2 \mathrm{~g} / \mathrm{L} / \mathrm{h}$, respectively. Unfortunately, the downstream enzymes of the BDO pathway displayed lower activity which might be due to product mediated inhibition, hence and also responsible for 4-HB accumulation in the medium. Later adopting the laboratory evolution method, the downstream enzymes Cat2 and $A L D$ were modified and the strain with these variants increased $20 \% 1$, 4-BDO production and $75 \%$ decline in $4-\mathrm{HB}$ accumulation. Further, research was continued on the elimination of by-products like acetate, ethanol, glutamate, and 4-aminobutyrate by driving the pyruvate to acetyl-CoA, and oxaloacetate, the addition of formate to improve cofactor regeneration, elimination of energy incompetent genes of electron transport chain, overexpression of membrane-bound transhydrogenase $(p n t A B)$ that synthesizes $\mathrm{NADPH}$ and $\mathrm{NAD}^{+}$, and temporary regulation of growth mediated protein expression to turn on during growth and off during the BDO production using protein degradation tags. After the series of modifications, 
a commercially viable strain was obtained that could produce $>125 \mathrm{~g} / \mathrm{L} 1,4-\mathrm{BDO}$, at $0.4 \mathrm{~g} / \mathrm{g}$ yield, and $3.5 \mathrm{~g} / \mathrm{L} / \mathrm{h}$ productivity (Burgard et al., 2016; Lee and Kim, 2015; https://www.genomatica.com/_uploads/pdfs/CEP-Magazine-A-bioengineering-platform-toindustrialize-biotechnology.pdf).

\subsubsection{Process modifications and optimization for improved $1,4-B D O$ production}

The process optimization criteria are to evaluate end product titres, yield, productivity, consistency or robustness, tolerance to substrates, inhibitors, intermediates, and products. We have already observed that enzymes involved in the central carbon metabolism, lower TCA cycle, and BDO synthesis pathway are very much important to regulate the synthesis. An increase in 2-fold activity of phosphofructokinase ( $p f k)$ increased DO production by 16 $20 \%$, similarly, the lower TCA cycle enzyme aconitase, citrate synthase, and isocitrate dehydrogenase improved BDO productivity by $2-6 \%$. As the BDO synthesis process requires high energy and reducing equivalents, increase in ATP synthase activity increased BDO productivity by $48.5 \%$ (Andreozzi et al., 2016). In the road to commercialization Genomatica process engineers have optimized the media components, aeration requirements (the composition of $\mathrm{CO}_{2}$ and $\mathrm{O}_{2}$ in the gas phase), provided final modifications to the strain by deleting the duplicated regions and IS elements to reduce the genome size, mutating tonA and lamb to confer phage resistance during the large scale fermentations, and removal of cryptic prophage to prevent the cell autolysis. By April 2016, a strain that can produce $\sim 140$

g/L was commercialized (Burgard et al., 2016; https://www.genomatica.com/_uploads/pdfs/CEP-Magazine-A-bioengineering-platform-toindustrialize-biotechnology.pdf). 
After 1, 3-PDO and 2, 3-PDO, 1, 4-BDO biological process was proved to be significant in terms of sustainability by reducing $83 \%$ carbon dioxide per $\mathrm{kg}$ BDO and $67 \%$ lower fossil energy usage compared to chemical process (Burgard et al., 2016).

\subsection{1, 3-Butanediol}

1, 3-Butanediol (1, 3 BDO) is an optically active four carbon glycol that is not biologically synthesized by any known pathways. As a diol, 1, 3-BDO is used as an intermediate in synthesis of plastics, polyesters, plasticizers, cosmetics, flavouring agents, humectants, pets and cattle feed. The optical isomer (R)-1, 3-BDO is used as a precursor for azetidinone derivatives, that are intermediates for synthesis of antibiotics, pheromones, fragrances, and insecticides. The recognition of (R)-1, 3-BDO as a valuable commodity chemical is due to its key application as an intermediate in synthesis of penem and carbapenem $\beta$-lactam antibiotics. These antibiotics are currently considered as most effective defence strategy against wide range of pathogenic microorganisms. In the conventional (R)-1, 3-BDO synthesis, the petrochemical feedstock acetylene is hydrated to acetaldehyde and 2 moles of acetaldehyde are converted to 3-hydroxybutanal and followed by hydration to (R)-1, 3-BDO. It is well known that petrochemical based process might be economical, but it comes with great concerns on climatic change and natural disasters. Hence there is a need for reliable and environmentally friendly process (Kataoka et al., 2020, 2017, 2013; Matsuyama et al., 2001; Kim et al., 2020).

\subsubsection{Microorganisms and physiology of $1,3-B D O$ pathway}

As a non-natural metabolite, there are no wild type microorganisms that can synthesize 1, 3BDO from any known natural or synthetic substrates. Although native biosynthetic pathway was lacking in the microorganisms, still they could transform the intermediate molecules to 1 , 
3-BDO. In 2013 an artificial biosynthetic pathway based on glucose as the carbon source was developed by Kataoka and his associates. This pathway is a reversed fatty acid $\beta$ oxidation process in which 2 acetyl-CoA molecules are condensed in the presence of 3-keto thiolase (phaA from Ralstonia eutropha) to produce acetoacetyl-CoA, in a consequent reactions NADPH dependent acetoacetyl CoA reductase (phaB from Ralstonia eutropha), and alcohol dehydrogenase converts acetoacetyl-CoA to (R)-1, 3-BDO. The recombinant $E$. coli strain expressing the heterologous pathway could produce $9.05 \mathrm{~g} / \mathrm{L}(\mathrm{R})-1,3-\mathrm{BDO}$ (Kataoka et al., 2013).

Recently a novel pathway was proposed which is less dependent on reducing equivalents and other cofactors and called as DERA (2-deoxyribose-5-phosphate aldolase) pathway. The end product of the glycolysis, pyruvate is converted to 2 acetaldehyde molecules in the presence of pyruvate decarboxylase, further these two acetaldehyde molecules undergo aldol condensation in the presence of 2-deoxyribose-5-phosphate aldolase to form 3hydroxybutanal, which is further reduced to (R)-1,3-BDO by NADPH dependent aldo-keto reductase (Nemr et al., 2018).

\subsubsection{Genetic manipulations for improved 1,3-BDO production}

The asymmetric reduction of 4-hydroxy-2-butanone (4H2B) to (R)-1, 3-BDO is catalysed by $2^{\circ}$ alcohol dehydrogenase $(C p S A D H)$ from Candida parapsiloris IFO 1396, which improved its activity 2 times when heterologously expressed in E. coli. Similarly, ADH enzymes from Candida arborea and Issatchenkia scutulata IFO 10070 have $99 \%$ enantio-selectivity towards (R)-1,3-BDO synthesis from 4H2B, and ADH from Kluyveromyces lactis IFO 1267 and $C$. parapsiloris IFO 1396, respectively, could produce $\sim 100 \mathrm{mM}$ (R)-1, 3-BDO and $\sim 70 \mathrm{mM}$ (S)-1, 3-BDO respectively (Matsuyama et al., 2001). With the vast knowledge in genomic data base, enzymes with higher ketone substrate specificity and reaction rates can be observed via initial characterization. A mutated Rhodococcus phenylacetaldehyde reductase 
or Leifsonia alcohol dehydrogenase could produce (R), and (S)-1,3-BDO with 99 and $87 \%$ enantio-selectivity respectively (Itoh et al., 2007).

Similarly, in the DERA 1, 3-BDO biosynthetic pathway, aldo-keto reductase (AKR) that converts 3-hydroxybutanal (3-HB) to (R)-1, 3-BDO should be specific to 3-HB but not to acetaldehyde. Hence a search was initiated to understand the enzyme repository for improved 3-HB substrate specificity and improved BDO production. The enzyme AKR in Pseudomonas aeruginosa (PA1127) has higher reactivity towards 3-HB and low substrate specificity towards acetaldehyde (Kim et al., 2017).

\subsubsection{Process modifications and optimization for improved 1, 3-BDO production}

Along with genetic engineering approaches, study related to media engineering, optimization, modes of reaction, influence of physiological and environmental factors would significantly increase the end-product titres and ideal scenarios on the road to commercialization. Initially two strategies developed for 1, 3-BDO production are (i) enzyme mediated asymmetric reduction of 4-hydroxy-2-butanone (Matsuyama et al., 2001), and (ii) enantio selective oxidation of racemic mixture to (R)-1,3-BDO (Matsuyama et al., 2001; Yamamoto et al., 2002). Though these strategies resulted in higher titres ( 72.6 g/L), yield (48\% from 15\% racemic mixture) and with $95 \%$ purity, the feedstocks used was petroleum derived. Itoh and associates developed an immobilized packed bed reactor process to improve the enzyme stability and co-factor regeneration by addition of external hydrogen donor 2-propanol. The E. coli cells expressing the mutated Rhodococcus phenylacetaldehyde reductase or Leifsonia alcohol dehydrogenase were immobilized in packed bed reactor and supplementing 2propanol without any additional supplementation of co-factors produced $49.5 \mathrm{~g} / \mathrm{L}(\mathrm{R})-1,3-$ BDO in a continuous mode with $5 \% \mathrm{w} / \mathrm{v} 4 \mathrm{H} 2 \mathrm{~B}$ feed in 500 hours, even $15 \%$ increased NADH dependent ADH activity was observed (Itoh et al., 2007). Along with formate dehydrogenase, addition of 2-propanol to the reaction medium could regenerate NADH 
molecules, this could be an advantage in developing reduction processes like diol formation. The metabolic load on the chassis strains by overexpression of formate dehydrogenase can be reduced, but additional studies to be carried out whether the desired enzyme is active in the presence of 2-propanol.

The expression of DERA pathway in E. coli was able to synthesize $0.3 \mathrm{~g} / \mathrm{L} 1,3-\mathrm{BDO}$, but the strain was evolved with series of optimizations resulting in $2.4 \mathrm{~g} / \mathrm{L} 1,3-\mathrm{BDO}$ with $56 \mathrm{mg} / \mathrm{g}$ yield (Kim et al., 2020). With limited knowledge on intermediates and co-factors synthetic pathways are constructed for 1,3-BDO production but the resulting titres and productivities are not comparable with commercial standards, furthermore intensive research should be carried out in strain engineering, media optimization and process development strategies to improve the yields and productivity.

\section{Biological production of $\mathrm{C5}$ diols}

Short chain diols have wide applications in the synthesis of polyesters, polyurethanes, and other products like $3 \mathrm{C}$ or $4 \mathrm{C}$ diols. Currently, pentanediols are produced by chemical process involving petroleum-based feedstocks like tetrahydrofuran, 1, 3-butadiene and acetylene. The processes involve multiple steps (hydrogenation, dehydration, hydration and hydrogenation) under unfavourable conditions and require expensive catalysts (Huang et al., 2017). Even the chemical process turned out to be costly due to limited availability of 5 carbon feedstocks from petrochemical sources. But biosynthetic pathways based on renewable resources or substrates to produce pentanediols are not identified and considered as non-natural metabolite like 1, 3-BDO and 1, 4-BDO. In systems biology approach, glycolytic products like pyruvate and acetyl-CoA are the precursors for the production of short chain alcohols and isoprenoids, fatty acid pathways produce long chain fatty acid alcohols or alkanes, and TCA cycle intermediates for short chain dicarboxylic and tricarboxylic acids. Similarly, amino acids can 
also act as the precursors, because of their functional groups at $\mathrm{N}$ and $\mathrm{C}$-terminal, abundance in the media components and as endogenous metabolites.

\subsection{1, 5-Pentanediol and 2, 4-Pentanediol}

In the lignocellulosic biomass mediated processes, the major challenges are the by-products of the initial pretreatment process like lignin and inhibitors like furfurals. Wang et al., proposed that microorganisms that could degrade furfurals through diols can be further investigated to block the pathway at specific point to accumulate 1, 5-pentanediol (Wang et al., 1994).

In the amino acid mediated pathway, the oxaloacetate produced from the TCA cycle is an important precursor to produce charged amino acids like aspartate, glutamate and lysine. These amino acids are further converted to $\omega$-hydroxylic acids (Figure 4) by sequential decarboxylation, transamination and reduction. 5-hydroxyvalerate produced by heterologous

expression of lysine 2-monooxygenase, 5-aminovaleramidase, aminobutyrate aminotransferase, and carboxylic acid reductase or alcohol dehydrogenase in E. coli HA1 strain results in $2.7 \mathrm{~g} / \mathrm{L} \mathrm{1,} \mathrm{5-} \mathrm{PDO} \mathrm{(Wang} \mathrm{et} \mathrm{al.,} \mathrm{2020).} \mathrm{Similarly,} \mathrm{L-threonine} \mathrm{based} \mathrm{pathway}$ was proposed for production of 2, 3-pentanediol. The physiology involves the production of 2, 3-pentanedione and further reduction to 2, 3-PDO (Figure 4)(Dussel, 1994; Wang et al., 2020).

Till date E. coli was used as the chassis strain for the production of non-natural diols, but the amino acid producers like Corynebacterium glutamicum, could be the potential hosts for the expression of pentanediol producing pathways. However, the research on development of bioprocesses for pentanediols is in its initial stages, hence approaches either in increasing the metabolic flux towards improved amino acid synthesis or finding a novel pathway derived 
from glucose or other renewable substrates would result in developing efficient and sustainable process.

\section{Limitations and challenges}

The biological production of chemical compounds like organic acids, alcohols, amino acids, and other $1^{0}$ and $2^{0}$ metabolites was successful, but production of diols either from pure sugars or renewable substrates is challenging as isomers like 1, 3-BDO, 1, 4-BDO, pentanediols are non-natural metabolites lacking the biosynthetic pathways.

The pre-requisites for the development of sustainable and economical processes are;

(i) development of the biological pathway with potential routes to utilize various cheap and renewable feedstocks obtained from industries or agricultural residues; (ii) an integrated biorefinery approach to produce an array of speciality or bulk products from the components of every feedstock; and (iii) development of an efficient downstream process to easily separate different spectrum of chemicals. In order to develop these bioprocesses advanced metagenomic, genome mining tools, in combination with prediction tools and metabolic models are required in selection of chassis strains, efficient pathway specific enzymes. Further tuning of these enzymes for improved activity, integration and expression of synthetic pathway in the heterologous expression results in efficient biocatalysts (Chung et al., 2015; Sabra et al., 2016; Zeng and Sabra, 2011a, 2011b; Zhang et al., 2017).

The other challenges involved in the upstream processes are optimizing and maintaining the environmental factors and the media components for the improved titres, yield and productivity of desired end metabolites. In a commercial scale point of view, the process should be economical and sustainable, if cost-effective carbon sources were employed in production. 


\section{Conclusion and future perspectives}

In the speciality and commodity chemicals C2-C5 diols represent the important category, as they are the building blocks for the most dependent plastic industry and, undergo polycondensation with a dicarboxylic acid resulting in polyesters (fig. 5). Currently these C2C5 diols are produced from fossil fuel derived feedstocks like ethylene, acetylene, butadiene, etc., but the products come with the price, a serious damage to global environment. Hence, there is an increasing demand for the environmentally friendly biological processes. In C2-C5 diols, 1, 3-PDO and 2, 3-BDO are the most successful commercially available chemicals. Several isomers like 1, 3-BDO, 1, 4-BDO, and pentanediols are non-natural metabolites and no available biological pathways to synthesize these compounds directly from the renewable substrates is available.

Initial in-silico pathway design and flux-based analysis provided with necessary information required for the construction of genetically engineered strains and further optimization and validation through process engineering approaches could result in commercially viable processes. However, in the commercial process, cost of the substrate adds up to $50 \%$ of the overall process cost, hence development of bioprocesses with capability of using various renewable feedstocks or industrial waste streams would be beneficial and economical. Furthermore, construction of an efficient microbial strain, which could produce higher titres of end product with high yields and productivity, without accumulation of undesired byproducts will make the downstream process simpler and cost-effective.

\section{Acknowledgement}

Sulfath Hakkim Hazeena and Maria Paul Alphy acknowledge Council of Scientific and Industrial Research and Academy of Scientific and Innovative Research (AcSIR) for providing resources to carry out doctoral studies. Raveendran Sindhu acknowledges Department of Science and Technology for sanctioning a project under DST WOS-B scheme. 


\section{References}

Akhtar, M.S., 2007. Paenibacillus polymyxa. Australas. Plant Pathol. 1, 293.

Altaras_2001_Conversion of Sugars to 1,2-Propanediol by Thermoanaerobacterium thermosaccharolyticum HG-8.pdf, n.d.

Andreozzi, S., Chakrabarti, A., Soh, K.C., Burgard, A., Yang, T.H., Van Dien, S., Miskovic, L., Hatzimanikatis, V., 2016. Identification of metabolic engineering targets for the enhancement of 1,4-butanediol production in recombinant E. coli using large-scale kinetic models. Metab. Eng. 35, 148-159. https://doi.org/10.1016/j.ymben.2016.01.009

Bennett, G.N., San, K.Y., 2001. Microbial formation, biotechnological production and applications of 1,2-propanediol. Appl. Microbiol. Biotechnol. 55, 1-9. https://doi.org/10.1007/s002530000476

Burgard, A., Burk, M.J., Osterhout, R., Van Dien, S., Yim, H., 2016. Development of a commercial scale process for production of 1,4-butanediol from sugar. Curr. Opin. Biotechnol. 42, 118-125. https://doi.org/10.1016/j.copbio.2016.04.016

Celińska, E., 2010. Debottlenecking the 1,3-propanediol pathway by metabolic engineering. Biotechnol. Adv. 28, 519-530. https://doi.org/10.1016/j.biotechadv.2010.03.003

Cho, S., Kim, T., Woo, H.M., Kim, Y., Lee, J., Um, Y., 2015a. High production of 2,3butanediol from biodiesel-derived crude glycerol by metabolically engineered Klebsiella oxytoca M1. Biotechnol. Biofuels 8, 146. https://doi.org/10.1186/s13068-015-0336-6

Cho, S., Kim, T., Woo, H.M., Lee, J., Kim, Y., 2015b. Enhanced 2 , 3-Butanediol Production by Optimizing Fermentation Conditions and Engineering Klebsiella oxytoca M1 through Overexpression of Acetoin Reductase 1-16. https://doi.org/10.1371/journal.pone.0138109 
Choi, E.J., Kim, J.W., Kim, S.J., Seo, S.O., Lane, S., Park, Y.C., Jin, Y.S., Seo, J.H., 2016. Enhanced production of 2,3-butanediol in pyruvate decarboxylase-deficient Saccharomyces cerevisiae through optimizing ratio of glucose/galactose. Biotechnol. J. 11, 1424-1432. https://doi.org/10.1002/biot.201600042

Chung, H., Yang, J.E., Ha, J.Y., Chae, T.U., Shin, J.H., Gustavsson, M., Lee, S.Y., 2015. Bio-based production of monomers and polymers by metabolically engineered $\begin{array}{lllll}\text { microorganisms. } & \text { Curr. } & \text { Opin. } & \text { Biotechnol. }\end{array}$ https://doi.org/10.1016/j.copbio.2015.07.003

Dabrowski, S., Zabłotna, E., Pietrewicz-Kubicz, D., Długołecka, A., 2012. Screening of environmental samples for bacteria producing: 1,3-propanediol from glycerol. Acta Biochim. Pol. 59, 353-356.

David, C., Schmid, A., Adrian, L., Wilde, A., Bühler, K., 2018. Production of 1,2propanediol in photoautotrophic Synechocystis is linked to glycogen turn-over. Biotechnol. Bioeng. 115, 300-311. https://doi.org/10.1002/bit.26468

David, C., Schmid, A., Bühler, K., 2019. Cellular physiology controls photoautotrophic production of 1,2-propanediol from pools of $\mathrm{CO}_{2}$ and glycogen. Biotechnol. Bioeng. 116, 882-892. https://doi.org/10.1002/bit.26883

Drozdzyńska, A., Leja, K., Czaczyk, K., 2011. Biotechnological production of 1,3propanediol from crude glycerol. Biotechnologia 92, 92-100. https://doi.org/10.5114/bta.2011.46521

Dussel, E., 1994. No Title이것은 임시도서. la "conquista" a la "colonización" del mundo la vida $1982,323$. 
Erian, A.M., Gibisch, M., Pflügl, S., 2018. Engineered E. coli W enables efficient 2,3butanediol production from glucose and sugar beet molasses using defined minimal medium as economic basis. Microb. Cell Fact. 17, 190. https://doi.org/10.1186/s12934-018-1038-0

Fages, J., Mulard, D., Rouquet, J.-J., Wilhelm, J.-L., 1986. 2,3-Butanediol production from Jerusalem artichoke, Helianthus tuberosus, by Bacillus polymyxa ATCC 12321. Optimization of kLa profile. Appl. Microbiol. Biotechnol. 25, 197-202. https://doi.org/10.1007/BF00253648

Fjölnisdóttir, B.L., Haraldsdóttir, P., Ingvadóttir, E.M., Scully, S.M., Örlygsson, J., 2018. Characterization of a 1,2-Propanediol Producing Escherichia Strain Isolated from a Geothermally Heated Intertidal Pool in Northern Iceland. Fine Focus 4, 19-39. https://doi.org/10.33043/ff.4.1.19-39

Fu, J., Huo, G., Feng, L., Mao, Y., Wang, Z., Ma, H., Chen, T., Zhao, X., 2016. Metabolic engineering of Bacillus subtilis for chiral pure meso-2,3-butanediol production. Biotechnol. Biofuels 9, 1-14. https://doi.org/10.1186/s13068-016-0502-5

Gallardo, R., Faria, C., Rodrigues, L.R., Pereira, M.A., Alves, M.M., 2014. Anaerobic granular sludge as a biocatalyst for 1,3-propanediol production from glycerol in continuous bioreactors. Bioresour. Technol. 155, 28-33. https://doi.org/10.1016/j.biortech.2013.12.008

Gaspar, P., Neves, A.R., Gasson, M.J., Shearman, C.A., Santos, H., 2011. High Yields of 2 , 3-Butanediol and Mannitol in Lactococcus lactis through Engineering of NAD 2 Cofactor Recycling $\quad \dagger \quad$ Appl. Environ. Microbiol. 77, 6826-6835. https://doi.org/10.1128/AEM.05544-11

Ge, Y., Li, K., Li, L., Gao, C., Zhang, L., Ma, C., Xu, P., 2016. Contracted but effective: production of enantiopure 2,3-butanediol by thermophilic and GRAS Bacillus licheniformis. 
https://doi.org/10.1039/c6gc01023g

Grover, B.P., Garg, S.K., Verma, J., 1990. Production of 2,3-butanediol from wood hydrolysate by Klebsiella pneumoniae. World J. Microbiol. Biotechnol. 6, 328-332. https://doi.org/10.1007/BF01201306

Gungormusler, M., Gonen, C., Ozdemir, G., Azbar, N., 2010. 1,3-Propanediol production potential of Clostridium saccharobutylicum NRRL B-643. N. Biotechnol. 27, 782-788. https://doi.org/10.1016/j.nbt.2010.07.010

Häßler, T., Schieder, D., Pfaller, R., Faulstich, M., Sieber, V., 2012. Enhanced fed-batch fermentation of 2,3-butanediol by Paenibacillus polymyxa DSM 365. Bioresour. Technol. 124, 237-244. https://doi.org/10.1016/j.biortech.2012.08.047

Huang, K., Brentzel, Z.J., Barnett, K.J., Dumesic, J.A., Huber, G.W., Maravelias, C.T., 2017. Conversion of Furfural to 1,5-Pentanediol: Process Synthesis and Analysis. ACS Sustain. Chem. Eng. 5, 4699-4706. https://doi.org/10.1021/acssuschemeng.7b00059

Huang, K.X., Rudolph, F.B., Bennett, G.N., 1999. Characterization of methylglyoxal synthase from Clostridium acetobutylicum ATCC 824 and its use in the formation of 1,2$\begin{array}{lllll}\text { propanediol. } & \text { Appl. } & \text { Environ. } & \text { Microbiol. } & 65\end{array}$ https://doi.org/10.1128/aem.65.7.3244-3247.1999

Ingvadottir, E.M., Scully, S.M., Orlygsson, J., 2017. Evaluation of the genus of Caldicellulosiruptor for production of 1,2-propanediol from methylpentoses. Anaerobe 47, 86-88. https://doi.org/10.1016/j.anaerobe.2017.04.015

Islam, Z. ul, Klein, M., Aßkamp, M.R., Ødum, A.S.R., Nevoigt, E., 2017. A modular metabolic engineering approach for the production of 1,2-propanediol from glycerol by Saccharomyces cerevisiae. Metab. Eng. 44, 223-235. 
https://doi.org/10.1016/j.ymben.2017.10.002

Itoh, N., Nakamura, M., Inoue, K., Makino, Y., 2007. Continuous production of chiral 1,3butanediol using immobilized biocatalysts in a packed bed reactor: Promising biocatalysis method with an asymmetric hydrogen-transfer bioreduction. Appl. Microbiol. Biotechnol. 75, 1249-1256. https://doi.org/10.1007/s00253-007-0957-1

Jain, R., Sun, X., Yuan, Q., Yan, Y., 2015. Systematically Engineering Escherichia coli for Enhanced Production of 1,2-Propanediol and 1-Propanol. ACS Synth. Biol. 4, 746-756. https://doi.org/10.1021/sb500345t

Jeon, E., Lee, S., Kim, D., Yoon, H., Oh, M., Park, C., Lee, J., 2009. Development of a Saccharomyces cerevisiae strain for the production of 1,2-propanediol by gene manipulation. Enzyme Microb. Technol. 45, 42-47. https://doi.org/10.1016/j.enzmictec.2009.03.009

Ji, X.-J., Huang, H., Ouyang, P.-K., 2011. Microbial 2,3-butanediol production: A state-of$\begin{array}{lllll}\text { the-art } & \text { review. } & \text { Biotechnol. } & \text { 351-364. }\end{array}$ https://doi.org/https://doi.org/10.1016/j.biotechadv.2011.01.007

Ju, J.H., Wang, D., Heo, S.Y., Kim, M.S., Seo, J.W., Kim, Y.M., Kim, D.H., Kang, S.A., Kim, C.H. and Oh, B.R., 2020. Enhancement of 1, 3-propanediol production from industrial by-product by Lactobacillus reuteri CH53. Microbial Cell Factories, 19(1),1-10. https://doi.org/10.1186/s12934-019-1275-X

Jung, M.Y., Jung, H.M., Lee, J., Oh, M.K., 2015. Alleviation of carbon catabolite repression in Enterobacter aerogenes for efficient utilization of sugarcane molasses for 2,3 butanediol production. Biotechnol. Biofuels 1-12. https://doi.org/10.1186/s13068-015-02903

Jung, S.-G., Jang, J.-H., Kim, A.-Y., Lim, M.-C., Kim, B., Lee, J., Kim, Y.-R., 2013. 
Removal of pathogenic factors from 2,3-butanediol-producing Klebsiella species by inactivating virulence-related wabG gene. Appl. Microbiol. Biotechnol. 97, 1997-2007. https://doi.org/10.1007/s00253-012-4284-9

Kataoka, N., Vangnai, A.S., Pongtharangkul, T., Yakushi, T., Matsushita, K., 2017. Production of 1,3-diols in Escherichia coli. Bioresour. Technol. 245, 1538-1541. https://doi.org/10.1016/j.biortech.2017.05.082

Kataoka, N., Vangnai, A.S., Tajima, T., Nakashimada, Y., Kato, J., 2013. Improvement of (R)-1,3-butanediol production by engineered Escherichia coli. J. Biosci. Bioeng. 115, 475480. https://doi.org/10.1016/j.jbiosc.2012.11.025

Kataoka, N., Vangnai, A.S., Ueda, H., Tajima, T., Nakashimada, Y., Kato, J., Zu, H., Gu, J., Zhang, H., Fan, A., Nie, Y., Nie, Y., Xu, Y., Xu, Y., Kim, T., Flick, R., Brunzelle, J., Singer, A., Evdokimova, E., Brown, G., Joo, J.C., Minasov, G.A., Anderson, W.F., Mahadevan, R., Savchenko, A., Yakunin, A.F., Stogios, P.J., Khusnutdinova, A.N., Nemr, K., Skarina, T., Flick, R., Joo, J.C., Mahadevan, R., Savchenko, A., Yakunin, A.F., 2020. Novel aldo-keto reductases for the biocatalytic conversion of 3- hydroxybutanal to 1,3-butanediol: Structural and biochemical studies. Biosci. Biotechnol. Biochem. 78, 1-11. https://doi.org/10.1080/09168451.2014.891933

Kaur, G., Srivastava, A.K., Chand, S., 2012. Advances in biotechnological production of 1,3propanediol. Biochem. Eng. J. 64, 106-118. https://doi.org/10.1016/j.bej.2012.03.002

Kim, S., Hahn, J., 2015. Efficient production of 2 , 3-butanediol in Saccharomyces cerevisiae by eliminating ethanol and glycerol production and redox rebalancing. Metab. Eng. 1-7. https://doi.org/10.1016/j.ymben.2015.07.006

Kim, S.J., Kim, J.W., Lee, Y.G., Park, Y.C., Seo, J.H., 2017. Metabolic engineering of 
Saccharomyces cerevisiae for 2,3-butanediol production. Appl. Microbiol. Biotechnol. 101, 2241-2250. https://doi.org/10.1007/s00253-017-8172-1

Kim, T., Flick, R., Brunzelle, J., Singer, A., Evdokimova, E., Brown, G., Joo, J.C., Minasov, G.A., Anderson, W.F., Mahadevan, R., Savchenko, A., Yakunin, A.F., 2017. Novel aldo-keto reductases for the biocatalytic conversion of 3- hydroxybutanal to 1,3-butanediol: Structural and biochemical studies. Appl. Environ. Microbiol. 83, 1-15. https://doi.org/10.1128/AEM.03172-16

Kim, T., Stogios, P.J., Khusnutdinova, A.N., Nemr, K., Skarina, T., Flick, R., Joo, J.C., Mahadevan, R., Savchenko, A., Yakunin, A.F., 2020. Rational engineering of 2-deoxyribose5-phosphate aldolases for the biosynthesis of (R)-1,3-butanediol. J. Biol. Chem. 295, 597609. https://doi.org/10.1074/jbc.RA119.011363

Köpke, M., Mihalcea, C., Liew, F., Tizard, J.H., Ali, M.S., Conolly, J.J., Al-Sinawi, B., Simpson, S.D., 2011. 2,3-Butanediol Production by Acetogenic Bacteria, an Alternative Route to Chemical Synthesis, Using Industrial Waste Gas. Appl. Environ. Microbiol. 77, 5467 LP - 5475. https://doi.org/10.1128/AEM.00355-11

Lee, M.J., Brown, I.R., Juodeikis, R., Frank, S., Warren, M.J., 2016. Employing bacterial microcompartment technology to engineer a shell-free enzyme-aggregate for enhanced 1,2propanediol production in Escherichia coli. Metab. Eng. 36, 48-56. https://doi.org/10.1016/j.ymben.2016.02.007

Lee, Y.G., Seo, J.H., 2019. Production of 2,3-butanediol from glucose and cassava hydrolysates by metabolically engineered industrial polyploid Saccharomyces cerevisiae. Biotechnol. Biofuels 12, 1-12. https://doi.org/10.1186/s13068-019-1545-1

Li, H., Liao, J.C., 2013. Engineering a cyanobacterium as the catalyst for the photosynthetic 
conversion of $\mathrm{CO}_{2}$ to 1,2-propanediol. Microb. Cell Fact. 12, 1-9. https://doi.org/10.1186/1475-2859-12-4

Li, L., Li, K., Wang, K., Chen, C., Gao, C., Ma, C., Xu, P., 2014. Efficient production of 2,3butanediol from corn stover hydrolysate by using a thermophilic Bacillus licheniformis strain. Bioresour. Technol. 170 $256-261$. https://doi.org/https://doi.org/10.1016/j.biortech.2014.07.101

Liu, H., Lu, T., 2015. Autonomous production of 1,4-butanediol via a de novo biosynthesis pathway in engineered Escherichia coli. Metab. Eng. 29, 135-141. https://doi.org/10.1016/j.ymben.2015.03.009

Lundin, A.P., Stewart, K.L., Stewart, A.M., Herring, T.I., Chowdhury, C., Bobik, T.A., 2020. Genetic characterization of a glycyl radical microcompartment used for 1,2-propanediol fermentation by uropathogenic Escherichia coli CFT073. J. Bacteriol. 202, 1-13. https://doi.org/10.1128/JB.00017-20

Ma, Z., Rao, Z., Xu, L., Liao, X., Fang, H., Zhuge, B., Zhuge, J., 2010. Expression of dha operon required for 1,3-PD formation in escherichia coli and Saccharomyces cerevisiae. Curr. Microbiol. 60, 191-198. https://doi.org/10.1007/s00284-009-9528-2

Maervoet, V.E.T., De Mey, M., Beauprez, J., De Maeseneire, S., Soetaert, W.K., 2011. Enhancing the microbial conversion of glycerol to 1,3-propanediol using metabolic engineering. Org. Process Res. Dev. 15, 189-202. https://doi.org/10.1021/op1001929

Maervoet, V.E., De Maeseneire, S.L., Avci, F.G., Beauprez, J., Soetaert, W.K. and De Mey, M., 2016. High yield 1, 3-propanediol production by rational engineering of the 3hydroxypropionaldehyde bottleneck in Citrobacter werkmanii. Microbial cell factories, 15(1), p.23. https://doi.org/10.1186/s12934-016-0421-y 
Martinez, S.B., Speckman, R.A., 1988. 2,3-Butanediol production from hydrolyzed whey permeate by immobilized cells of Bacillus polymyxa. Appl. Biochem. Biotechnol. 18, 303313. https://doi.org/10.1007/BF02930834

Matsuyama, A., Yamamoto, H., Kawada, N., Kobayashi, Y., 2001. Industrial production of (R)-1,3-butanediol by new biocatalysts. J. Mol. Catal. - B Enzym. 11, 513-521. https://doi.org/10.1016/S1381-1177(00)00032-1

Motwani, M., Seth, R., Daginawala, H.F., Khanna, P., 1993. Microbial production of 2,3butanediol from water hyacinth. Bioresour. Technol. 44, 187-195. https://doi.org/10.1016/0960-8524(93)90151-Z

Nakashimada, Y., Marwoto, B., Kashiwamura, T., Kakizono, T., Nishio, N., 2000. Enhanced 2,3-butanediol production by addition of acetic acid in Paenibacillus polymyxa. J. Biosci. Bioeng. 90, 661-664. https://doi.org/https://doi.org/10.1016/S1389-1723(00)90013-6

Narisetty, V., Astray, G., Gullón, B., Castro, E., Parameswaran, B., Pandey, A., 2017. Improved 1,3-propanediol production with maintained physical conditions and optimized media composition: Validation with statistical and neural approach. Biochem. Eng. J. 126, 109-117. https://doi.org/10.1016/j.bej.2017.07.003

Nemr, K., Müller, J.E.N., Joo, J.C., Gawand, P., Choudhary, R., Mendonca, B., Lu, S., Yu, X., Yakunin, A.F., Mahadevan, R., 2018. Engineering a short, aldolase-based pathway for (R)-1,3-butanediol production in Escherichia coli. Metab. Eng. 48, 13-24. https://doi.org/10.1016/j.ymben.2018.04.013

Ng, C.Y., Jung, M.Y., Lee, J., Oh, M.K., 2012. Production of 2,3-butanediol in Saccharomyces cerevisiae by in silico aided metabolic engineering. Microb. Cell Fact. 11, 1. https://doi.org/10.1186/1475-2859-11-68 
Nichols, T.M., Kennedy, N.W., Tullman-Ercek, D., 2020. A genomic integration platform for heterologous cargo encapsulation in 1,2-propanediol utilization bacterial microcompartments. Biochem. Eng. J. 156, 107496. https://doi.org/10.1016/j.bej.2020.107496

Niimi, S., Suzuki, N., Inui, M., Yukawa, H., 2011. Metabolic engineering of 1,2-propanediol pathways in Corynebacterium glutamicum. Appl. Microbiol. Biotechnol. 90, 1721-1729. https://doi.org/10.1007/s00253-011-3190-х

Niu, W., Guo, J., 2015. Stereospecific microbial conversion of lactic acid into 1,2propanediol. ACS Synth. Biol. 4, 378-382. https://doi.org/10.1021/sb500240p

Niu, W., Kramer, L., Mueller, J., Liu, K., Guo, J., 2019. Metabolic engineering of Escherichia coli for the de novo stereospecific biosynthesis of 1,2-propanediol through lactic acid. Metab. Eng. Commun. 8, 1-9. https://doi.org/10.1016/j.mec.2018.e00082

Okonkwo, C.C., Ujor, V.C., Mishra, P.K., Ezeji, T.C., n.d. Process Development for Enhanced 2 , 3-Butanediol Production by Paenibacillus polymyxa DSM 365 1-15. https://doi.org/10.3390/fermentation3020018

Perego, P., Converti, A., Del Borghi, A., Canepa, P., 2000. 2,3-Butanediol production by Enterobacter aerogenes: selection of the optimal conditions and application to food industry residues. Bioprocess Eng. 23, 613-620. https://doi.org/10.1007/s004490000210

Pflügl, S., Marx, H., Mattanovich, D., Sauer, M., 2014. Heading for an economic industrial upgrading of crude glycerol from biodiesel production to 1,3-propanediol by Lactobacillus $\begin{array}{llll}\text { diolivorans. } & \text { Bioresour. } & \text { Technol. } & \text { 499-504. }\end{array}$ https://doi.org/10.1016/j.biortech.2013.11.041

Plegaria, J.S., Sutter, M., Ferlez, B., Aussignargues, C., Niklas, J., Poluektov, O.G., Fromwiller, C., Teravest, M., Utschig, L.M., Tiede, D.M., Kerfeld, C.A., 2017. Structural and 
Functional Characterization of a Short-Chain Flavodoxin Associated with a Noncanonical 1,2-Propanediol Utilization Bacterial Microcompartment. Biochemistry 56, 5679-5690. https://doi.org/10.1021/acs.biochem.7b00682

Przystałowska, H., Zeyland, J., Szymanowska-Powałowska, D., Szalata, M., Słomski, R. and Lipiński, D., 2015. 1, 3-Propanediol production by new recombinant Escherichia coli containing genes from pathogenic bacteria. Microbiological research, 171, 1-7.

Raynaud, C., Lee, J., Sarçabal, J.L., Croux, C., Meynial-Salles, I., Soucaille, P., 2011. Molecular characterization of the glycerol-oxidative pathway of Clostridium butyricum VPI 1718. J. Bacteriol. 193, 3127-3134. https://doi.org/10.1128/JB.00112-11

Rodriguez, A., Wojtusik, M., Ripoll, V., Santos, V.E., Garcia-Ochoa, F., 2016. 1,3Propanediol production from glycerol with a novel biocatalyst Shimwellia blattae ATCC 33430: Operational conditions and kinetics in batch cultivations. Bioresour. Technol. 200, 830-837. https://doi.org/10.1016/j.biortech.2015.10.061

Sabra, W., Groeger, C., Zeng, A.P., 2016. Microbial cell factories for diol production. Adv. Biochem. Eng. Biotechnol. 155, 165-197. https://doi.org/10.1007/10_2015_330

Sánchez-Riera, F., Cameron, D.C., Cooney, C.L., 1987. Influence of environmental factors in the production of R(-)-1, 2-propanediol by Clostridium thermosaccharolyticum. Biotechnol. Lett. https://doi.org/10.1007/BF01027450

Satam_2019_Techno-economic analysis of 1,4-butanediol production by a single-step bioconversion process.pdf, n.d.

Saxena, R.K., Anand, P., Saran, S., Isar, J., Agarwal, L., 2010. Microbial production and applications of 1,2-propanediol. Indian J. Microbiol. 50, 2-11. https://doi.org/10.1007/s12088-010-0017-X 
Schilling, C., Ciccone, R., Sieber, V. and Schmid, J., 2020. Engineering of the 2, 3butanediol pathway of Paenibacillus polymyxa DSM 365. Metabolic Engineering, 61, 381388. https://doi.org/10.1016/j.ymben.2020.07.009

Silva_2020_Identification of Potential Technologies for 1, 4-Butanediol Production using Prospecting Methodology.pdf, n.d.

Suzuki, T., Onishi, H., 1968. Aerobic dissimilation of 1-rhamnose and the production of 1rhamnonic acid and 1,2-propanediol by yeasts. Agric. Biol. Chem. 32, 888-893. https://doi.org/10.1080/00021369.1968.10859143

Tran-Din, K. and gerhard G., 1985. Hicrobielogy. Arch Microbiol 87-92.

Van Den Broek, L.A.M., Knoop, R.J.I., Kappen, F.H.J., Boeriu, C.G., 2015. Chitosan films and blends for packaging material. Carbohydr. Polym. 116, 237-242. https://doi.org/10.1016/j.carbpol.2014.07.039

Vivek, N., Aswathi, T. V., Sven, P.R., Pandey, A., Binod, P., 2017. Self-cycling fermentation for 1,3-propanediol production: Comparative evaluation of metabolite flux in cell recycling, simple batch and continuous processes using Lactobacillus brevis N1E9.3.3 strain. J. Biotechnol. 259, 110-119. https://doi.org/10.1016/j.jbiotec.2017.07.033

Vivek, N., Hazeena, S.H., Rajesh, R.O., Godan, T.K., Anjali, K.B., Nair, L.M., Mohan, B., Nair, S.C., Sindhu, R., Pandey, A., Binod, P., 2019. Genomics of Lactic Acid Bacteria for Glycerol Dissimilation. Mol. Biotechnol. 61, 562-578. https://doi.org/10.1007/s12033-019$00186-2$

Vivek, N., Pandey, A., Binod, P., 2016. Biological valorization of pure and crude glycerol into 1,3-propanediol using a novel isolate Lactobacillus brevis N1E9.3.3. Bioresour. Technol. 213, 222-230. https://doi.org/10.1016/j.biortech.2016.02.020 
Vivek, N., Rajesh, R.O., Godan, T.K., Pandey, A. and Binod, P., 2019. White Biotechnology for Polymer Building Blocks: Strategies for Enhanced Production of Bio-based 1, 3Propanediol and Its Applications. In Green Chemistry for Surface Coatings, Inks and Adhesives. 145-182. https://doi.org/10.1039/9781788012997-00145

Wang, J., Li, C., Zou, Y., Yan, Y., 2020. Bacterial synthesis of C3-C5 diols via extending amino acid catabolism. Proc. Natl. Acad. Sci. U. S. A. 117, 19159-19167. https://doi.org/10.1073/pnas.2003032117

Wang, P., Brenchley, J.E., Humphrey, A.E., 1994. Screening microorganisms for utilization of furfural and possible intermediates in its degradative pathway. Biotechnol. Lett. 16, 977982. https://doi.org/10.1007/BF00128637

Wischral, D., Zhang, J., Cheng, C., Lin, M., De Souza, L.M.G., Pessoa, F.L.P., Pereira, N., Yang, S.T., 2016. Production of 1,3-propanediol by Clostridium beijerinckii DSM 791 from crude glycerol and corn steep liquor: Process optimization and metabolic engineering. Bioresour. Technol. 212, 100-110. https://doi.org/10.1016/j.biortech.2016.04.020

Wu_2016_Metabolic Burden.pdf, n.d.

Xin, B., Wang, Y., Tao, F., Li, L., Ma, C., Xu, P., 2016. Co-utilization of glycerol and lignocellulosic hydrolysates enhances anaerobic 1,3-propanediol production by Clostridium diolis. Sci. Rep. 6, 1-10. https://doi.org/10.1038/srep19044

Yamamoto, H., Matsuyama, A., Kobayashi, Y., 2002. Synthesis of (R)-1,3-butanediol by enantioselective oxidation using whole recombinant Escherichia coli cells expressing (S)specific secondary alcohol dehydrogenase. Biosci. Biotechnol. Biochem. 66, 925-927. https://doi.org/10.1271/bbb.66.925

Yan, P.F., Feng, J., Dong, S., Wang, M., Khan, I.A., Wang, Y., 2017. Production of High 
Levels of Chirally Pure d -2,3-Butanediol with a Newly Isolated Bacillus Strain. ACS Sustain. Chem. Eng. 5, 11016-11023. https://doi.org/10.1021/acssuschemeng.7b02910

Yang, B., Liang, S., Liu, H., Liu, J., Cui, Z., Wen, J., 2018. Metabolic engineering of Escherichia coli for 1,3-propanediol biosynthesis from glycerol, Bioresource Technology. https://doi.org/10.1016/j.biortech.2018.07.082

Yang, T.-W., Rao, Z.-M., Zhang, X., Xu, M.-J., Xu, Z.-H., Yang, S.-T., 2013. Effects of corn steep liquor on production of 2,3-butanediol and acetoin by Bacillus subtilis. Process Biochem. 48, 1610-1617. https://doi.org/https://doi.org/10.1016/j.procbio.2013.07.027

Yang, T., Rao, Z., Zhang, X., Xu, M., Xu, Z., Yang, S.T., 2013. Improved Production of 2,3Butanediol in Bacillus amyloliquefaciens by Over-Expression of Glyceraldehyde-3Phosphate Dehydrogenase and 2,3-butanediol Dehydrogenase. PLoS One 8, 1-9. https://doi.org/10.1371/journal.pone.0076149

Yi, H.-S., Ahn, Y.-R., Song, G.C., Ghim, S.-Y., Lee, S., Lee, G., Ryu, C.-M., 2016. Impact of a Bacterial Volatile 2,3-Butanediol on Bacillus subtilis Rhizosphere Robustness. Front. Microbiol. 7, 993. https://doi.org/10.3389/fmicb.2016.00993

Yun, J., Zabed, H.M., Zhang, Y., Parvez, A., Zhang, G. and Qi, X., 2020. Co-fermentation of glycerol and glucose by a co-culture system of engineered Escherichia coli strains for 1, 3propanediol production without vitamin B12 supplementation. Bioresource Technology, 319, p.124218. https://doi.org/10.1016/j.biortech.2020.124218

Zeng, A.P., 2019. New bioproduction systems for chemicals and fuels: Needs and new $\begin{array}{llll}\text { development. } & \text { Biotechnol. } & \text { Adv. } & \text { 508-518. }\end{array}$ https://doi.org/10.1016/j.biotechadv.2019.01.003

Zeng, A.P., Sabra, W., 2011a. Microbial production of diols as platform chemicals: Recent 
$\begin{array}{lllll}\text { progresses. } & \text { Curr. } & \text { Opin. } & \text { Biotechnol. } & \text { 22, }\end{array}$ https://doi.org/10.1016/j.copbio.2011.05.005

Zeng, A.P., Sabra, W., 2011b. Microbial production of diols as platform chemicals: Recent $\begin{array}{lllll}\text { progresses. } & \text { Curr. } & \text { Opin. } & \text { Biotechnol. } & \text { 22, }\end{array}$ https://doi.org/10.1016/j.copbio.2011.05.005

Zhang, L., Cao, C., Jiang, R., Xu, H., Xue, F., Huang, W., Ni, H., Gao, J., 2018. Production of R,R-2,3-butanediol of ultra-high optical purity from Paenibacillus polymyxa ZJ-9 using homologous recombination. Bioresour. Technol. 261, 272-278. https://doi.org/10.1016/j.biortech.2018.04.036

Zhang, Y., Liu, D., Chen, Z., 2017. Production of C2-C4 diols from renewable bioresources: New metabolic pathways and metabolic engineering strategies. Biotechnol. Biofuels 10, 120. https://doi.org/10.1186/s13068-017-0992-9

Zhou_2019_Metabolic engineering of Pseudomonas denitrificans for the 1,3-propanediol.pdf, n.d.

Zhou, S., Lama, S., Sankaranarayanan, M., Park, S., 2019. Metabolic engineering of Pseudomonas denitrificans for the 1,3-propanediol production from glycerol. Bioresour. Technol. 292, 121933. https://doi.org/10.1016/j.biortech.2019.121933 


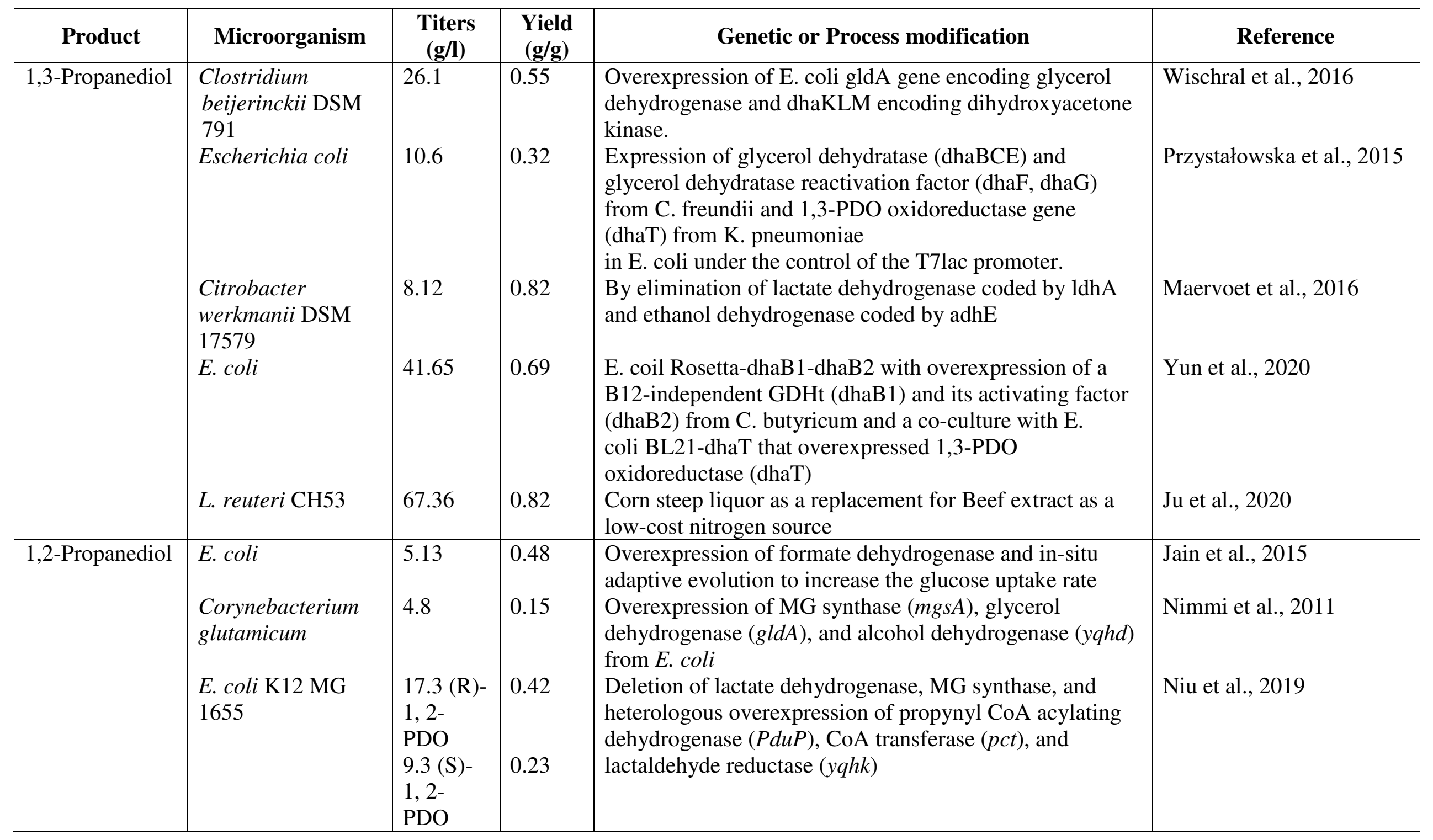




\begin{tabular}{|c|c|c|c|c|c|}
\hline 2,3-Butanediol & $\begin{array}{l}\text { Paenibacillus } \\
\text { polymyxa DSM } \\
365 \\
\text { Klebsiella oxytoca } \\
\text { Paenibacillus } \\
\text { polymyxa } \\
\text { Bacillus } \\
\text { amyloliquifaciens } \\
\text { Bacillus subtilis } \\
\\
\text { Bacillus } \\
\text { licheniformis } \\
\text { E.coli } \\
\text { Sacharomyces } \\
\text { cerevisiae } \\
\text { S. cerevisiae } \\
\end{array}$ & $\begin{array}{l}142.5 \\
25.88 \\
132.9 \\
103.7 \\
\text { g/L } \\
123.7 \\
68.1 \\
2.29 \\
72.9\end{array}$ & $\begin{array}{l}0.46 \\
0.44 \\
0.113 \\
0.41\end{array}$ & $\begin{array}{l}\text { Deletion of lactate dehydrogenase, constitutive } \\
\text { episomalexpression of butanediol dehydrogenase, } \\
\text { CRISPR Cas9 mediated genome editing for elimination of } \\
\text { exopolysaccharide production by knocking out sacB gene. } \\
\text { Overexpression of acetoin reductase (AR) } \\
\text { Deletion of diacetyl reductase gene } \\
\text { Over-Expression of } \\
\text { Glyceraldehyde-3-Phosphate Dehydrogenase and bdh } \\
\text { Deletion of D-2,3-BDO dehydrogenase, } \\
\text { Phosphotransacetylase, lactate dehydrogenase, } \\
\text { heterologous overexpression of acetolactate synthase and } \\
\text { meso-2,3-BDO dehydrogenase } \\
\text { Deletion of meso-2,3-BDO dehydrogenase } \\
\text { Deletion of alcohol dehydrogenase, } \\
\text { Phosphotransacetylase, and lactate dehydrogenase, } \\
\text { Deletion of alcohol dehydrogenase (adh 1, adh3, and } \\
\text { adh5) } \\
\text { Deletion of ethanol and glycerol assimilatory pathways } \\
\text { and overexpression of } \alpha \text {-acetolactate synthase (AlsS), } \alpha \text { - } \\
\text { acetolactate decarboxylase (AlsD), and 2,3- } \\
\text { butanediol dehydrogenase (Bdh1) } \\
\text { Disruption of pyruvate decarboxylase, alcohol } \\
\text { dehydrogenase and heterologous overexpression of } \\
\text { bacterial BDO pathway }\end{array}$ & $\begin{array}{l}\text { Ge et al., } 2016 \\
\text { Erian et al., } 2018 \\
\text { Ng et al., } 2012 \\
\text { Kim and Hahn, } 2015\end{array}$ \\
\hline 1,4-Butanediol & $\begin{array}{l}\text { E. coli } \\
\text { E. coli }\end{array}$ & 125 & 0.35 & $\begin{array}{l}\text { Deletion of succinic semialdehyde dehydrogenase, } \\
\text { chromosome integration of heterologous BDO pathway } \\
\text { genes under the expression of constitutive promoters. } \\
\text { overexpression of membrane-bound transhydrogenase } \\
\text { (pntAB), regulation of growth mediated protein }\end{array}$ & $\begin{array}{l}\text { Lee and Kim, } 2015 \\
\text { Burgard et al., } 2016\end{array}$ \\
\hline
\end{tabular}




\begin{tabular}{|c|c|c|c|c|c|}
\hline & & & & $\begin{array}{l}\text { expression, elimination of energy incompetent genes of } \\
\text { electron transport chain, and addition of formate to } \\
\text { improve cofactor regeneration }\end{array}$ & \\
\hline 1,3-Butanediol & $\begin{array}{l}\text { E. coli } \\
\text { E. coli } \\
\text { E. coli }\end{array}$ & $\begin{array}{l}9.05 \\
49.5 \\
2.45\end{array}$ & 0.056 & $\begin{array}{l}\text { Recombinant heterologous pathway } \\
\text { Heterologous overexpression of phenylacetaldehyde } \\
\text { reductase or alcohol dehydrogenase with additional } \\
\text { supplementation of 2-propanol and co-factors } \\
\text { Recombinant heterologous pathway }\end{array}$ & $\begin{array}{l}\text { Kataoka et al., } 2013 \\
\text { Itoh et al., } 2007 \\
\text { Kim et al., } 2020\end{array}$ \\
\hline
\end{tabular}




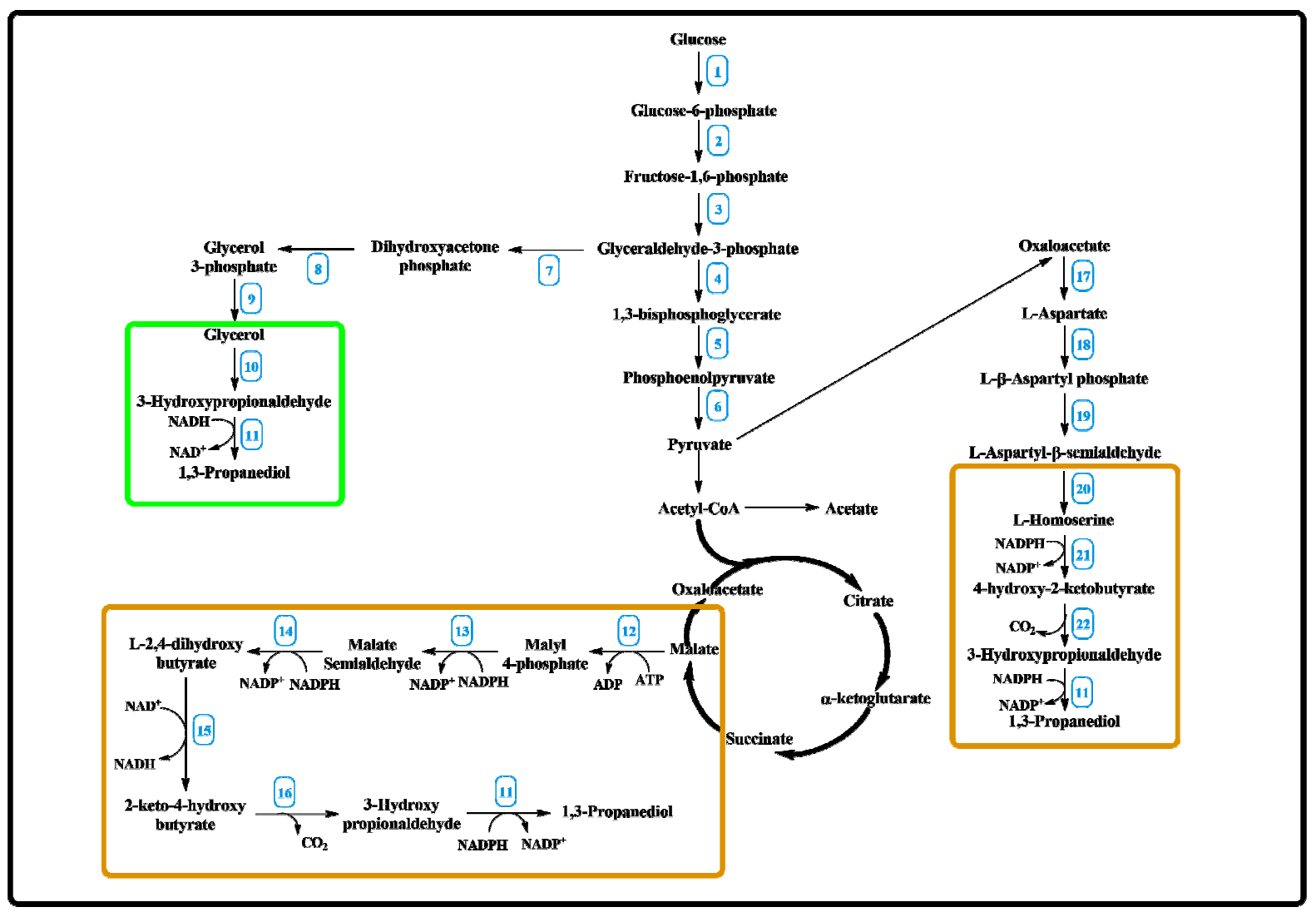

Fig.1. Metabolic pathways for the production of 1,3-propanediol (Green: natural; Orange: Artificial or synthetic pathways) Abbreviations: (1) hexokinase; (2) phosphoglucose isomerase; phosphofructokinase; (3) aldolase; (4) G-3-P dehydrogenase; (5) phosphoglycerate kinase; (6) mutase; (7) triose phosphate isomerase; (8) glycerol-3phosphate dehydrogenase; (9) glycerol-1-phosphatase; (10) glycerol dehydratase; (11) 1,3PDO oxidoreductase; (12) malate kinase; (13) malate semi aldehyde dehydrogenase; (14) malate semi aldehyde reductase; (15) DHB dehydrogenase; (16) OHB decarboxylase; (17) aspartate transaminase; (18) aspartate kinase; (19) aspartate semialdehyde dehydrogenase; (20) homoserine dehydrogenase; (21) homoserine dehydrogenase; and (22) OHB decarboxylase. 


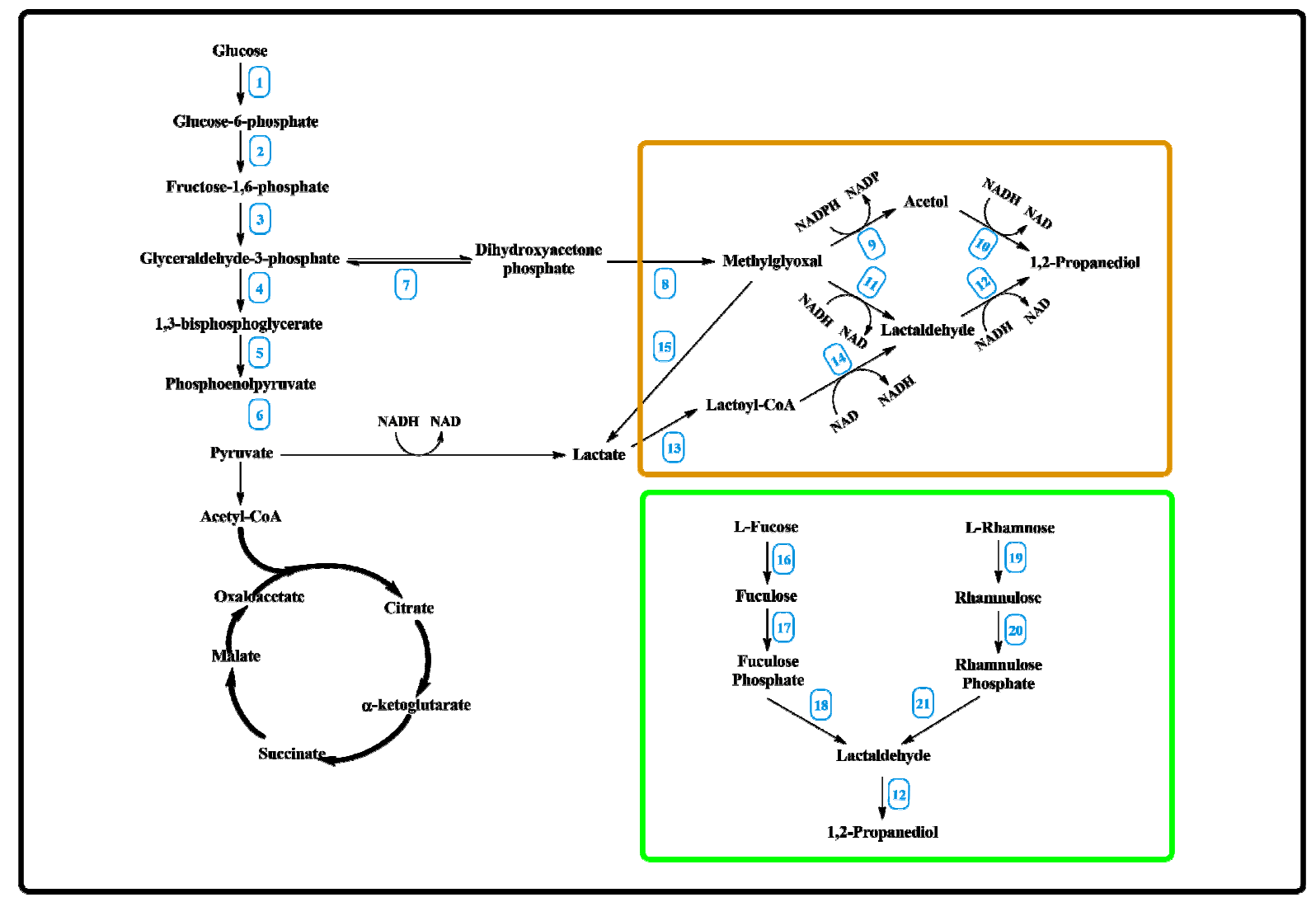

Fig.2. Metabolic pathways for the production of 1,2-propanediol (Green: natural; Orange: Artificial or synthetic pathways) Abbreviations: (1) hexokinase; (2) phosphoglucose isomerase; phosphofructokinase; (3) aldolase; (4) G-3-P dehydrogenase; (5) phosphoglycerate kinase; (6) mutase; (7) triose phosphate isomerase; (8) methyl glyoxal synthease; (9 and 12) alcohol dehydrogenase; (10 and 11) glycerol dehydrogenase; (13) lactoyl CoA transferase; (14) CoA acylating aldehyde dehydrogenase; (15) glyoxalase; (16) L-fucose isomerase; (17) L-fuculokinase (18) D-fuculose-1-phosphate aldolase; (19) Lrhamnose isomerase; (20) L-rhamnulokinase; and (21) D-rhamulose-1-phosphate aldolase. 


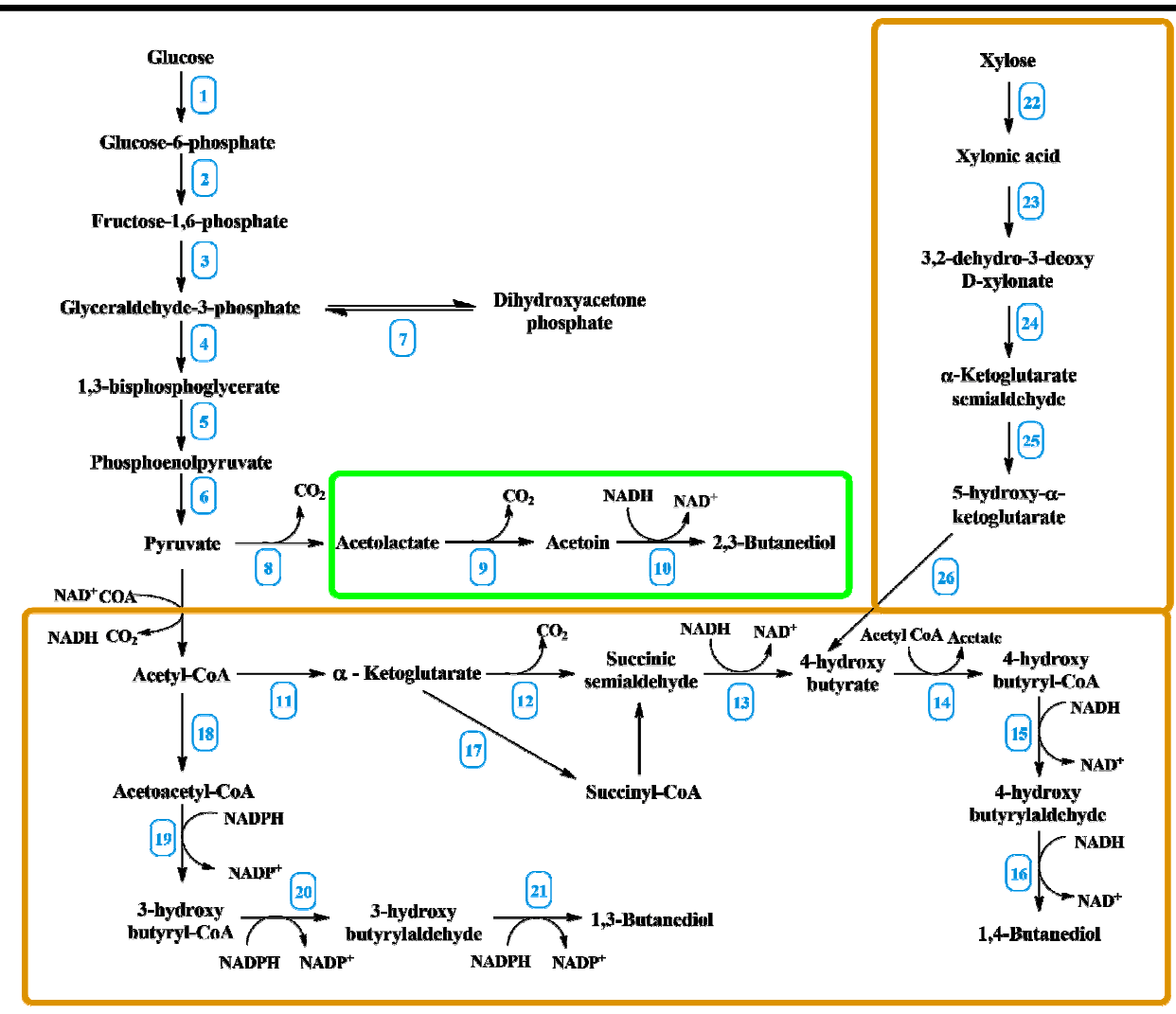

Fig.3. Metabolic pathways for the production of 2,3-BDO, 1,4-BDO and 1,3-BDO (Green: natural; Orange: Artificial or synthetic pathways) Abbreviations: (1) hexokinase; (2) phosphoglucose isomerase; phosphofructokinase; (3) aldolase; (4) G-3-P dehydrogenase; (5) phosphoglycerate kinase; (6) mutase; (7) triose phosphate isomerase; (8) acetolactate synthase; (9) acetolactate decarboxylase;(10) 2,3-BDO dehydrogenase; (11) TCA cycle enzymes; (12) ketoacid decarboxylase; (13) 4-hydroxybutyrate dehydrogenase; (14) 4hydroxy butyrate CoA transferase; (15) 4-hydroxybutyrate CoA reductase; (16) alcohol reductase (17) oxidoreductase; (18) 3-keto thiolase; (19) acetoacetyl CoA reductase; (20) butyryl CoA dehydrogenase; (21) alcohol dehydrogenase; (22) D-xylose dehydrogenase; (23) D-xylonate dehydratase; (24) 2-dehydro-3-deoxy-D-xylonate dehydratase; (25) KG semialdehyde dehydrogenase; and (26) ketoisovalerate decarboxylase. 


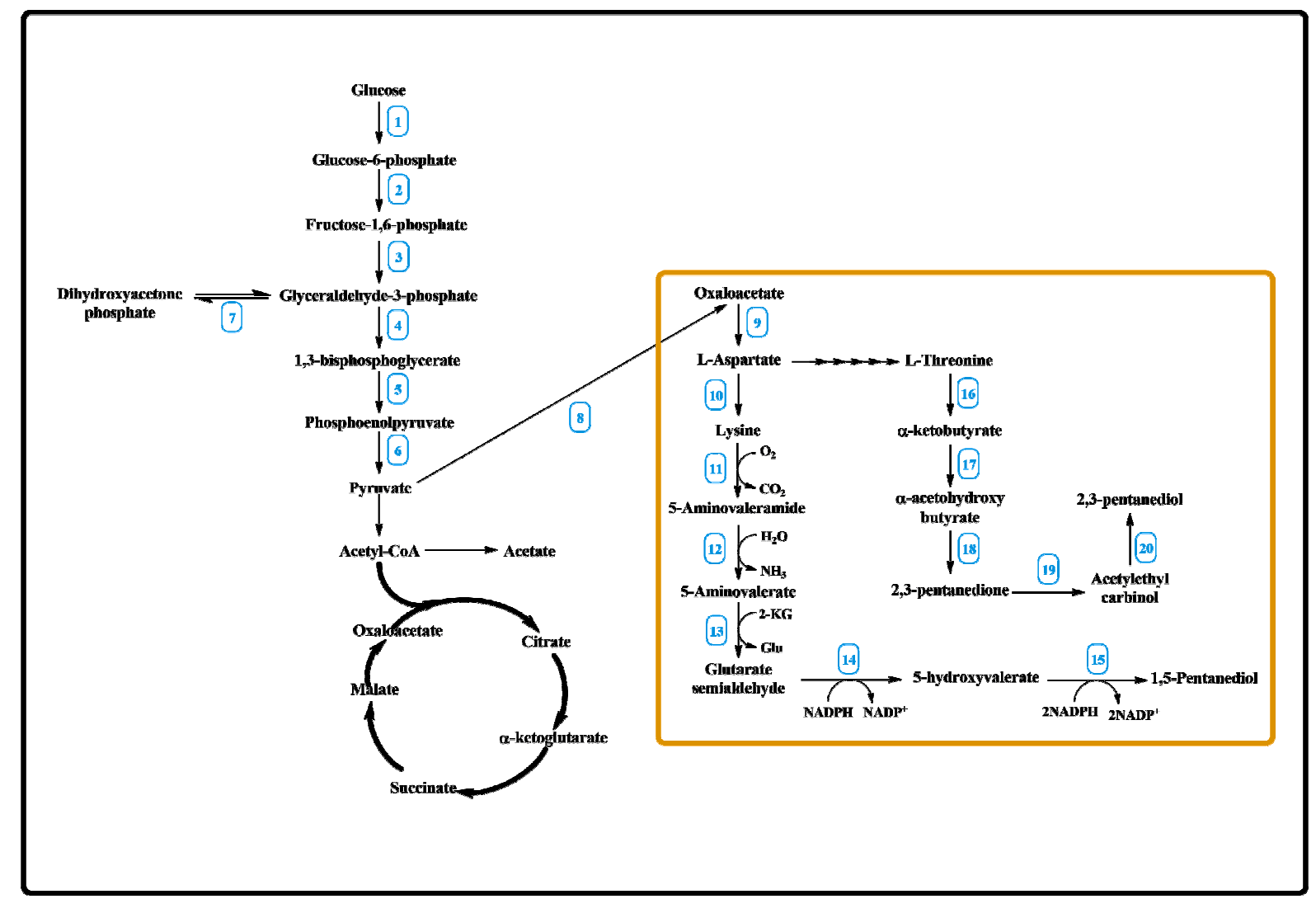

Fig.4. Metabolic pathways for the production of 1,5-pentanediol and 2,3-pentanediol (Orange: Artificial or synthetic pathways) Abbreviations: (1) hexokinase; (2) phosphoglucose isomerase; phosphofructokinase; (3) aldolase; (4) G-3-P dehydrogenase; (5) phosphoglycerate kinase; (6) mutase; (7) triose phosphate isomerase; (8) (9) (10) (11) lysine 2-monooxygenase; (12) 5-aminovaleramidase; (13) aminobutyrate aminotransferase; (14) alcohol dehydrogenase; (15) carboxylic acid reductase or alcohol dehydrogenase; (16) deaminase or dehydratase; (17) $\alpha$-acetohydroxy butyrate synthase; (18) decarboxylase; (19 and 20) diol dehydrogenase. 


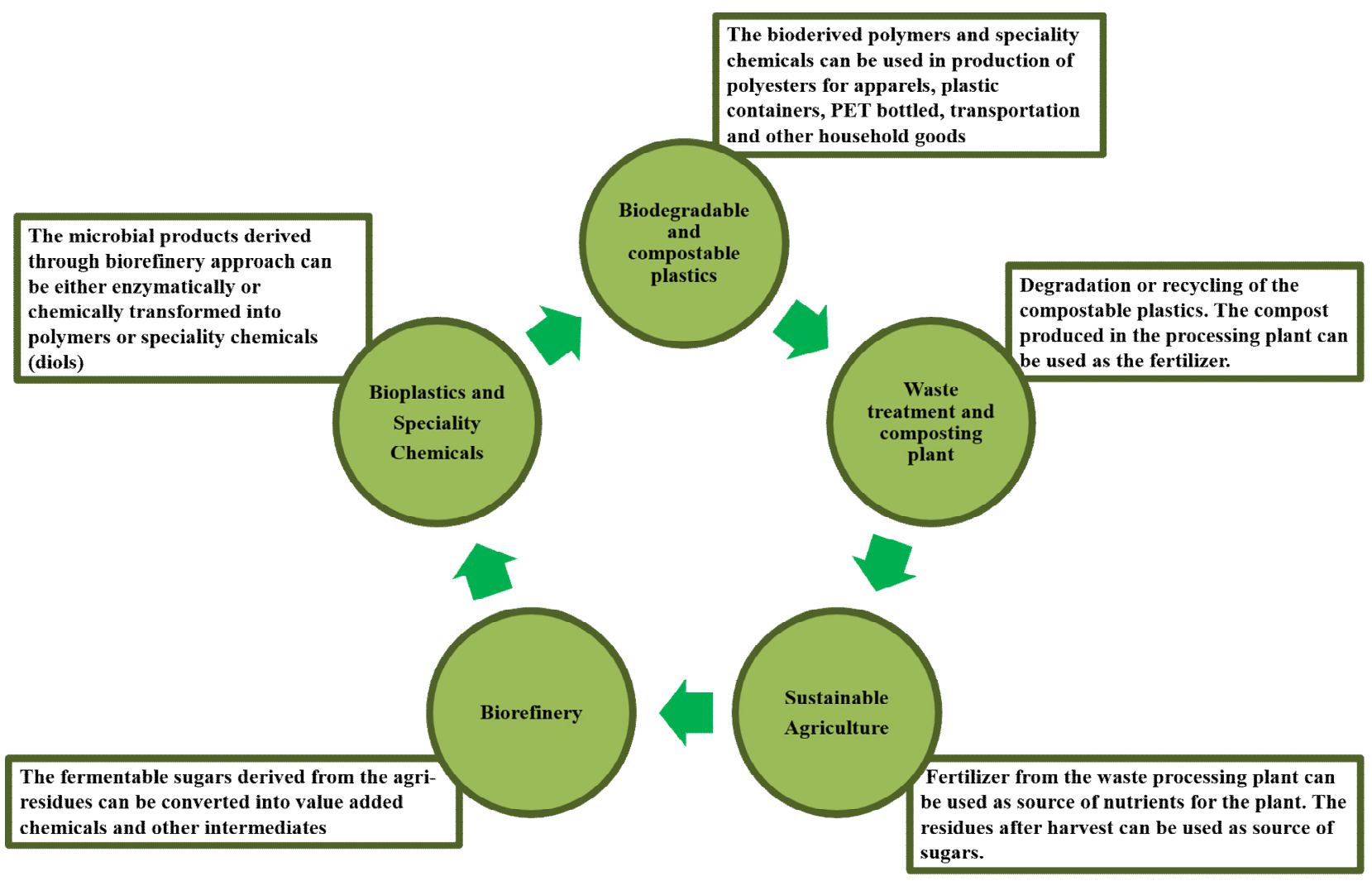

Fig.5. Speciality and commodity chemicals C2-C5 diols represent an important category, as building blocks for the most dependent plastic industry and, undergo polycondensation with a dicarboxylic acid resulting in polyesters 